\title{
Concerted Interneuron Activity in the Cerebellar Molecular Layer During Rhythmic Oromotor Behaviors
}

\author{
Guadalupe Astorga, ${ }^{1}$ Dongdong Li, ${ }^{1,2}$ ㄴ Ludivine Therreau, ${ }^{1}$ Merouann Kassa, ${ }^{1}$ Alain Marty, ${ }^{1}$ and Isabel Llano ${ }^{1}$ \\ ${ }^{1}$ Laboratoire de Physiologie Cérébrale, Centre National de la Recherche Scientifique and Université Paris Descartes, 75006 Paris, France, and ${ }^{2}$ Inserm \\ U1130, Centre National de la Recherche Scientifique Unité Mixte de Recherche 8246, Université Pierre et Marie Curie, Neuroscience Paris Seine/Institut de \\ Biologie Paris-Seine, Sorbonne Universities, 75005 Paris, France
}

Molecular layer interneurons (MLIs, stellate and basket cells) of the cerebellar cortex are linked together by chemical and electrical synapses and exert a potent feedforward inhibition on Purkinje cells. The functional role of MLIs during specific motor tasks is uncertain. Here, we used two-photon imaging to study the patterns of activity of neighboring individual MLIs in the Crus II region of awake female mice during two types of oromotor activity, licking and bruxing, using specific expression of the genetically encoded calcium indicator protein GCaMP6s. We found that both stellate and basket cells engaged in synchronized waves of calcium activity during licking and bruxing, with high degrees of correlation among the signals collected in individual MLIs. In contrast, no calcium activity was observed during whisking. MLI activity tended to lag behind the onset of sustained licking episodes, indicating a regulatory action of MLIs during licking. Furthermore, during licking, stellate cell activity was anisotropic: the coordination was constant along the direction of parallel fibers (PFs), but fell off with distance along the orthogonal direction. These results suggest a PF drive for $\mathrm{Ca}^{2+}$ signals during licking. In contrast, during bruxing, MLI activity was neither clearly organized spatially nor temporally correlated with oromotor activity. In conclusion, MLI activity exhibits a high degree of correlation both in licking and in bruxing, but spatiotemporal patterns of activity display significant differences for the two types of behavior.

Key words: behaving mice; cerebellum; inhibition; interneurons; two-photon imaging

\section{Significance Statement}

It is known that, during movement, the activity of molecular layer interneurons (MLIs) of the cerebellar cortex is enhanced. However, MLI-MLI interactions are complex because they depend both from excitatory electrical synapses and from potentially inhibitory chemical synapses. Accordingly, the pattern of MLI activity during movement has been unclear. Here, during two oromotor tasks, licking and bruxism, individual neighboring MLIs displayed highly coordinated activity, showing that the positive influences binding MLIs together are predominant. We further find that spatiotemporal patterns differ between licking and bruxing, suggesting that the precise pattern of MLI activity depends on the nature of the motor task.

\section{Introduction}

Stellate and basket cells of the mammalian cerebellar cortex, collectively called molecular layer interneurons (MLIs), exert a

Received April 23, 2017; revised 0ct. 10, 2017; accepted Oct. 17, 2017.

Author contributions: G.A. and I.L. designed research; G.A., L.T., and M.K. performed research; G.A., D.L., M.K., A.M., and I.L. analyzed data; A.M. and I.L. wrote the paper.

This work was supported by the Agence Nationale de la Recherche (Projects INNET and NUTRIPATHOS) and the European Research Council (Grant SINGLESITE). G.A. was supported by a postdoctoral fellowship from the Neuropole de Recherche Francilien (NeRF). We thank L. Looger, J. Akerboom, and D.S. Kim from the GENIE Project, Janelia Farm Research Campus, for the GCaMP6 plasmids.

The authors declare no competing financial interests.

G. Astorga's present address: Rockefeller University, 230 York Avenue, New York, NY 10065.

Corresponding author: Isabel Llano, Laboratoire de Physiologie Cérébrale, CNRS and Université Paris Descartes,

45 rue des Saints Pères, 75006 Paris, France. E-mail: isabel.Ilano@parisdescartes.fr.

DOI:10.1523/JNEUROSCI.1091-17.2017

Copyright $\odot 2017$ the authors $\quad 0270-6474 / 17 / 3711455-14 \$ 15.00 / 0$ strong feedforward inhibition on Purkinje cells (PCs) (Eccles et al., 1966). After excitatory parallel fiber (PF) input, MLI-driven inhibition sharply curtails the duration of $\mathrm{PC}$ responses and restricts the spread of these responses along the parasagittal plane (Cohen and Yarom, 2000; Mittmann et al., 2005; Santamaria et al., 2007; Dizon and Khodakhah, 2011; Blot et al., 2016; for review: Jörntell et al., 2010). In addition to this feedforward action, MLIs are interconnected through both chemical (Eccles et al., 1966; Chavas and Marty, 2003) and electrical (Mann-Metzer and Yarom, 1999; Alcami and Marty, 2013; Kim et al., 2014) synapses. The driving force for chemical MLI-MLI synapses as measured in brain slices is weak so that some of these synapses are excitatory, whereas others are inhibitory (Chavas and Marty, 2003). However, the intracellular $\mathrm{Cl}^{-}$concentration varies after changes in metabolic state (Rheims et al., 2009; for review, see Zilberter et al., 
2010), slicing-induced cell damage (Dzhala et al., 2012), and network activity (Thompson and Gähwiler, 1989; Astorga et al., 2015), so it is unclear to what extent conclusions concerning functional effects of chemical MLI-MLI synapses in slices are applicable to a more preserved environment including in vivo preparations. It is in particular unclear whether the MLI network engages into an organized spatiotemporal pattern of electrical activity in vivo as reported under special pharmacological conditions in slices (Middleton et al., 2008). In vivo studies show that MLI electrical activity increases after sensory stimulation (Jörntell and Ekerot, 2003) and during locomotion (Ozden et al., 2012, Jelitai et al., 2016). Because these studies were performed either using single unit recordings (Jörntell and Ekerot, 2003, Jelitai et al., 2016) or averaged multicellular imaging (Ozden et al., 2012), information concerning MLI-MLI interactions and network activity is difficult to extract. Altogether, in vivo activity of the MLI network presumably results from a combination of spontaneous electrical activity (Häusser and Clark, 1997), coordinating effects of electrical synapses, potentially inhibitory effects of chemical synapses, excitatory synaptic inputs from PF and climbing fibers (Carter and Regehr, 2002; Szapiro and Barbour, 2007), and inhibitory synaptic inputs from PC collaterals (Orduz and Llano, 2007; Witter et al., 2016). However, it is presently not known how these diverse and partially contradictory influences shape the collective electrical activity of the MLI network.

To start addressing these issues, we examined MLI activity patterns in behaving mice and explored the temporal and spatial characteristics of MLI activity during motor behavior. Mice expressing the genetically encoded $\mathrm{Ca}^{2+}$ indicator (GECI) GCaMP6s specifically in MLIs were imaged under head-fixed conditions and the resulting $\mathrm{Ca}^{2+}$-dependent fluorescence signals in MLIs were analyzed during the performance of a motor task. We focused our attention on licking because this is a rhythmic, sharply timed activity and because there is strong evidence for an association of specific cerebellar neuronal activity with this behavior. Earlier electrophysiological recordings showed changes in the temporal pattern of PCs complex spikes during rhythmic licking (Welsh et al., 1995) and following studies indicate a strong temporal correlation between the pattern of simple PC spikes and individual licks (Bryant et al., 2010; Cao et al., 2012). Recently, chronic window imaging of mice expressing GECIs in PCs showed that $\mathrm{Ca}^{2+}$ rises in PC dendrites correlated with licking activity (Gaffield et al., 2016).

In the present work we show that MLI activity is strongly engaged during both licking and another form of motor behavior, bruxing. In both cases, MLIs display highly synchronized $\mathrm{Ca}^{2+}$ rises. During licking, MLI activity shows a sharp synchronization with the onset of licking episodes and anisotropic decay of MLI-MLI coordination as a function of distance along the parasagittal versus coronal directions. The results shed light on the mechanisms governing activity of the MLI network during specific motor tasks.

\section{Materials and Methods}

Procedures. Experimental procedures complied with animal care guidelines of the University Paris Descartes and were approved by the "Prefecture de Police" (\#A-750607) in agreement with the European Directive 86/609/EEC and by the ethical committee of the University Paris Descartes.

Cranial window implantation. Female parvalbumin (PV)-Cre mice (postnatal days 27-36) were injected in the Crus II region of the cerebellar right hemisphere (stereotactic coordinates $-6.5 \mathrm{~mm}$ anteroposterior and $2.5 \mathrm{~mm}$ mediolateral) with an AAV1.Syn.Flex.GCaMP6s.WPRE. SV40 virus obtained from the University of Pennsylvania Vector Core facility following procedures described in detail in Astorga et al. (2015). Three weeks after injection, mice were anesthetized by intraperitoneal injection of ketamine $(14.8 \mu \mathrm{g} / \mathrm{g})$ and xylane $(10 \mu \mathrm{g} / \mathrm{g})$ and mounted in a stereotaxic frame. Eyes were protected from dehydration with eye ointment and lidocaine $(0.2 \%)$ was applied subcutaneously in the scalp. The skin overlying the frontal, parietal, and interparietal cranial bones was removed and a custom-made titanium fixation piece was attached to the frontoparietal junction with dental adhesive (Super-bond C\&B; Sun Medical). A $3 \mathrm{~mm}$ craniotomy was drilled in the interparietal bone around the injection site with posterior-lateral limits in the border of the occipital bone. A round glass coverslip ( $3 \mathrm{~mm}$ diameter; Warner Instruments) was placed over cerebellar regions Crus I and Crus II and kept in direct contact with the brain using a custom-made stainless steel ring ( 0.4 $\mathrm{mm}$ thick). The bone surrounding the craniotomy was thinned to allow access of a $20 \times$ objective while imaging and was covered with a thin layer of dental adhesive. One dose of enrofloxacin $(5 \mu \mathrm{g} / \mathrm{g})$ was given after the surgery to avoid infections and buprenorphine $(0.1 \mu \mathrm{g} / \mathrm{g})$ was given twice daily for $2-5 \mathrm{~d}$ to reduce pain. To avoid brain inflammation after surgery, 2 doses of dexamethasone $(2 \mu \mathrm{g} / \mathrm{g})$ were given intramuscularly in the quadriceps, respectively, $24 \mathrm{~h}$ and $30 \mathrm{~min}$ before cranial window implantation. Mice were allowed to recover from surgery in their cages for 1 week with ad libitum access to water. In optimal conditions, cranial windows remained clear for imaging up to 2 months.

Mouse habituation. Mice were water restricted for 15-20 h and habituated to head fixation in the imaging setup with ad libitum access to water for 15-20 min daily for 1 week before the first imaging session. Mice were weighed daily to ensure that body weight did not drop $>20 \%$ of its value before water restriction.

In a separate series of experiments designed to test the influence of water availability on licking parameters, three Swiss mice (one female and two males) aged $30 \mathrm{~d}$ were water restricted and habituated to headfixed conditions. A solenoid valve was added to the water delivery circuit allowing computer control of water availability. Mice were subjected to 1 head-fixed session per day for $9 \mathrm{~d}$. In each session, licking was monitored for 15-20 min, during which 10-12 trials were performed. Each trial consisted of 15-20 s of closed-valve conditions, followed immediately by $30-45 \mathrm{~s}$ of open-valve conditions. The electrical signal associated with licking was recorded as described below for imaging experiments.

In vivo imaging in awake mice. Schematics of the recording setup are shown in Figure $1 A$. Mice were head fixed with a tilt of $\sim 30^{\circ}$ while their limbs had direct contact with an aluminum sheet to monitor licking (see below). A heating blanket $\left(28-30^{\circ} \mathrm{C}\right.$; DC Temperature Control System) was placed under the aluminum sheet to keep a comfortable body temperature for the mice. Two-photon laser scanning imaging was performed in the posterior part of the Crus II region with a custom-built setup (for details, see Franconville et al., 2011). Imaging was performed at different depths into the molecular layer. Cells at imaging planes containing PC somata, which are recognizable as large, fluorescenceexcluding cell bodies surrounded by fluorescence-expressing basket-like structures (Fig. 1D), were considered to be basket cells. Otherwise, the cells were considered to be stellate cells. Excitation wavelength of the laser (MaiTai; Spectra Physics) was set at $910 \mathrm{~nm}$. The photodetector was a photomultiplier tube placed proximal to the imaging plane to maximize photon collection. Sequences of images were acquired using custommade routines in IgorPro with a time resolution of $140-230 \mathrm{~ms} /$ frame (10 $\mu \mathrm{s} /$ pixel) and had a color depth of 16 bits. A video camera (Logitech Webcam C260) from which the infrared filter was removed was used to monitor the orofacial movements with a time resolution of $15 \mathrm{~Hz}$. Infrared LEDs were used to illuminate the mouse face without altering the signal seen by the photodetector.

Licking activity was recorded reliably with high temporal precision using a standard analog-to-digital converter as described previously (Hayar et al., 2006). Water flowed out of the lick port at a rate of $\sim 8$ drops per minute and mice drank 1 drop of water $(\sim 40 \mu$ l volume) in several licks, varying from trial to trial. Typically, mice drank during the first 20 min after access to water and later showed intermittently grooming behaviors including teeth trimming (also called bruxing) and boggling for up to $2 \mathrm{~h}$. When the mice showed signs of discomfort, the imaging session was stopped and the animal was returned to its cage.

Spatial and temporal correlation analysis of $\mathrm{Ca}^{2+}$ activity versus motor behavior. Individual lick events (examples in Fig. $1 E$ ) were identified 
A

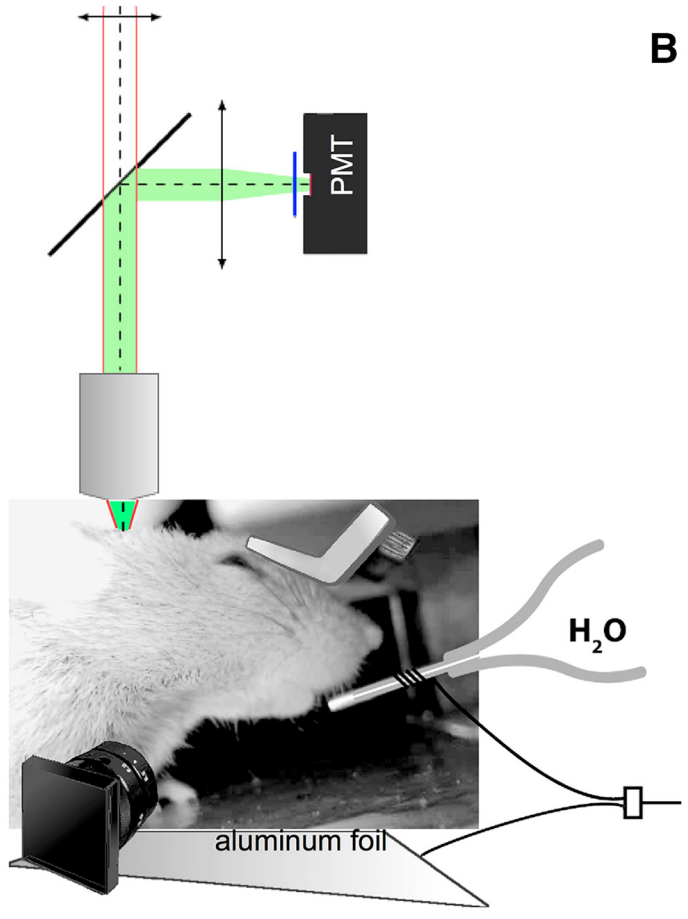

B
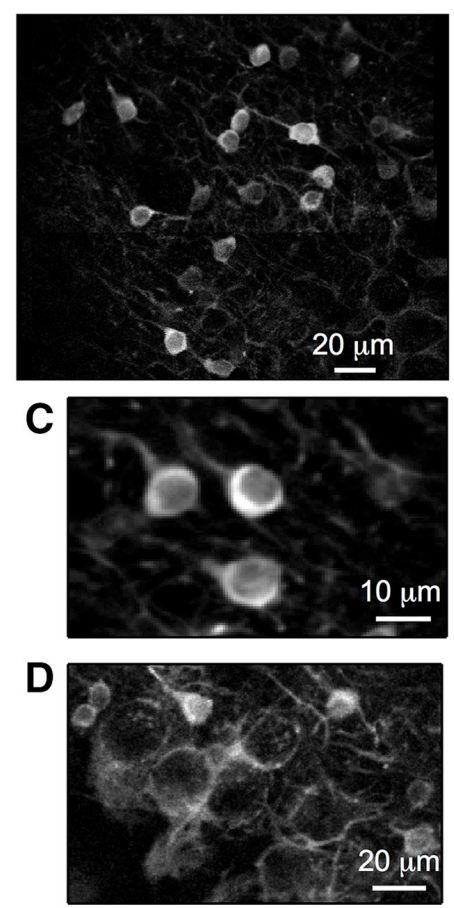
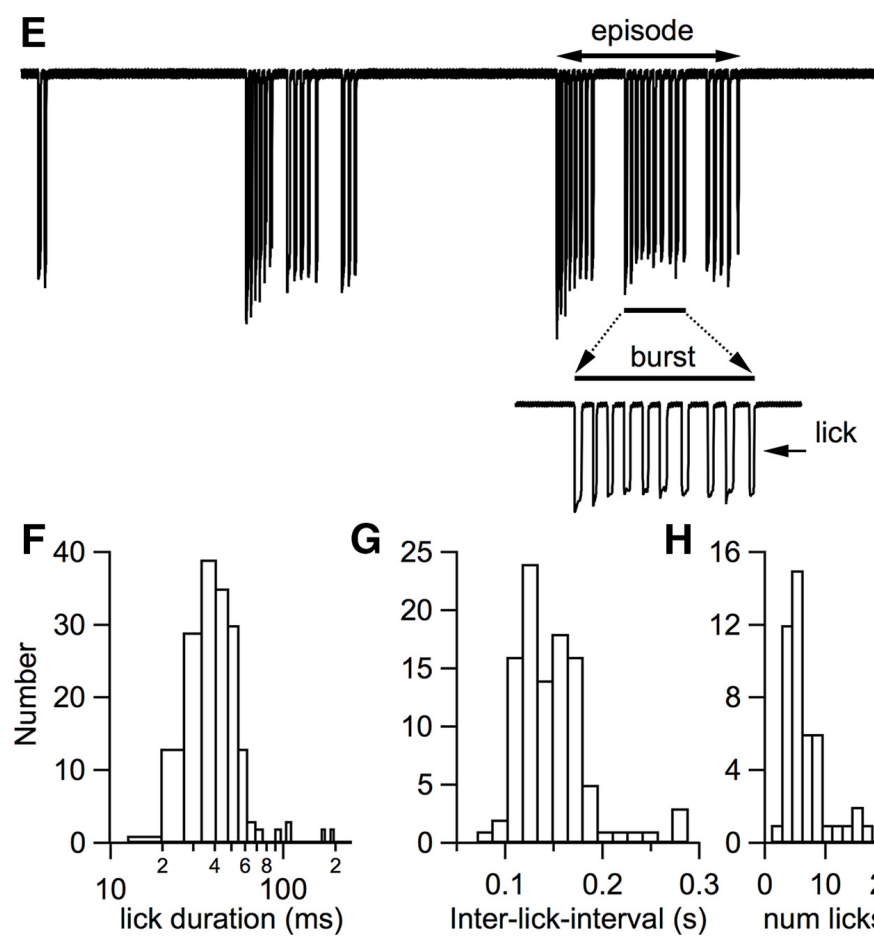

G

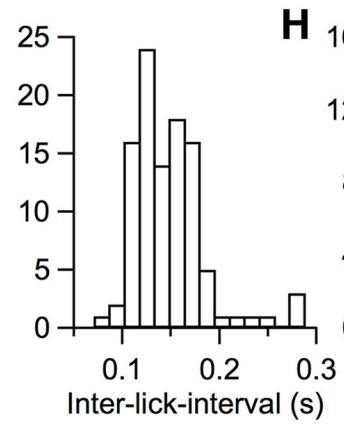

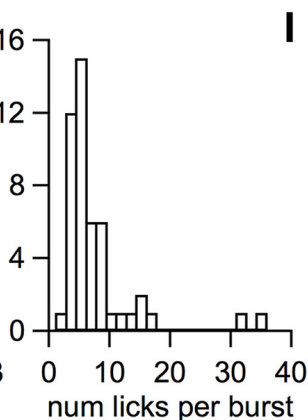

I
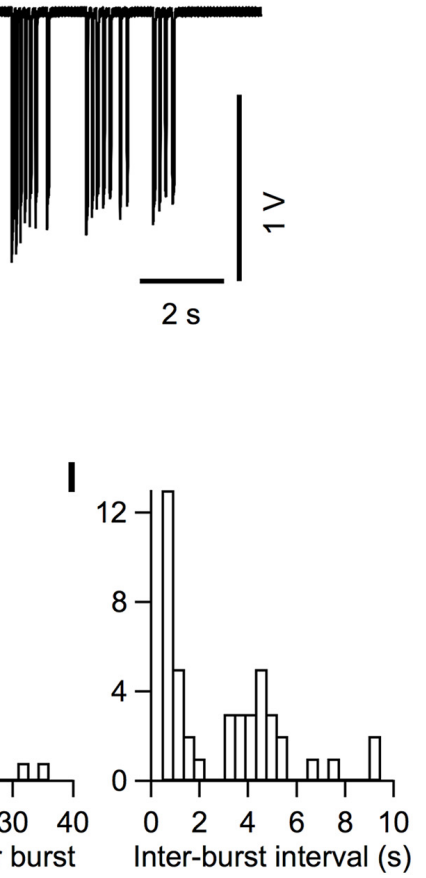

Figure 1. Chronic window imaging of the cerebellar cortex in mice performing rhythmic licking. $\boldsymbol{A}$, Experimental setup for two-photon laser-scanning Ca ${ }^{2+}$ imaging in head-fixed awake mice. Mice were head-fixed with a chronically implanted custom-made titanium piece, as depicted in the image. All experiments were performed in Crus II. Water was delivered through a metal tube with a copper cable soldered around it. This cable was connected to an A/D converter. Mice were in direct contact with an aluminum-covered platform that was connected to the ground of the A/D converter. Each lick closed an electrical circuit and was recorded as the junction potential between the metal tube and water. An infrared sensitive video camera was used to record orofacial behaviors. $\boldsymbol{B}$, Representative image from the molecular layer showing GCaMP6s expressing interneurons in a PV-Cre mouse (see Materials and Methods). $\boldsymbol{C}$, Average image of a smaller field in the molecular layer showing three stellate cells expressing GCaMP6s. D, z-projection of 15 images at $1.5 \mu \mathrm{m}$ steps in the vicinity of the PC layer. PCs do not express GCaMP6s and their dark somata are surrounded by basket cell axons. $\boldsymbol{E}$, Representative licking signals recorded when the mouse tongue touched the water. A single licking event is reflected by a pulse of potential change. A portion of the licking trace above the bar is enlarged to show a licking burst. $\boldsymbol{F}$, Distribution of individual lick duration, with a mean \pm SEM of $48.2 \pm 3.1 \mathrm{~ms}$ ( $n=284$ ). $\boldsymbol{G}$, Distribution of the ILIs, with a mean of $138.0 \pm$ $3.7 \mathrm{~ms}(n=103)$. Values were derived from licking events within single bursts, where a burst is defined as a temporal block comprising consecutive licks with ILIs $<0.5 \mathrm{~s}$. $\boldsymbol{H}$, Distribution of the numbers of lick events within a single burst, with a mean of $6.7 \pm 0.9(n=48) . I$, Distribution of the interburst intervals, with a median of $2.9 \pm 0.3 \mathrm{~s}(n=44)$. Data were pooled from 13 recordings in $n=4$ mice. 
A1

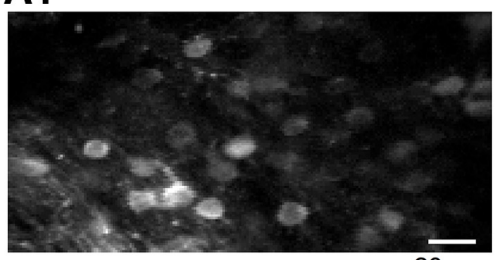

$20 \mu \mathrm{m}$

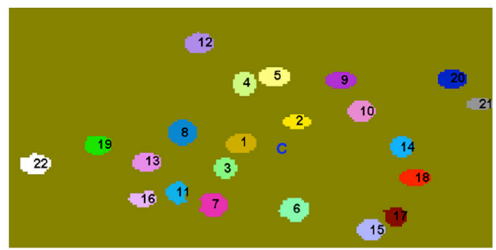

A2
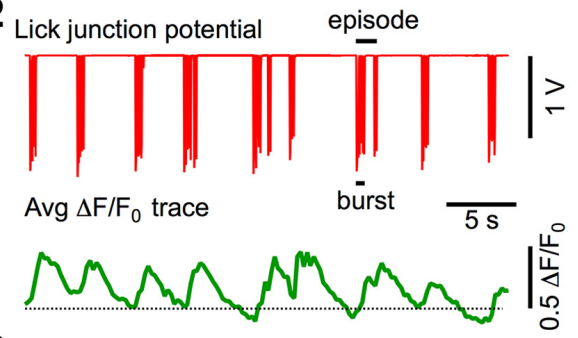

A3

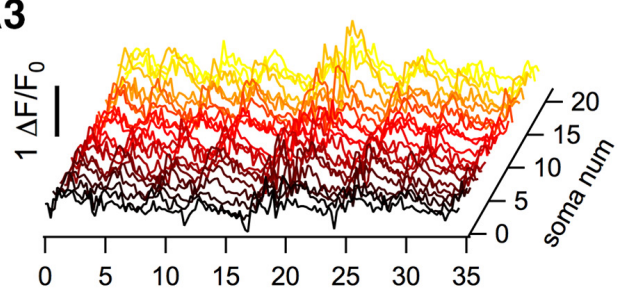

(s)
B

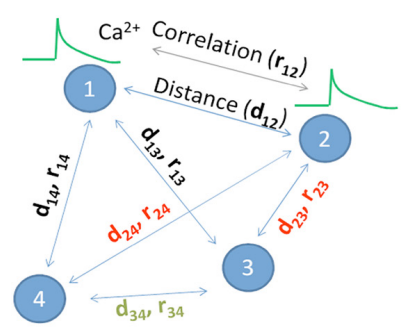

C

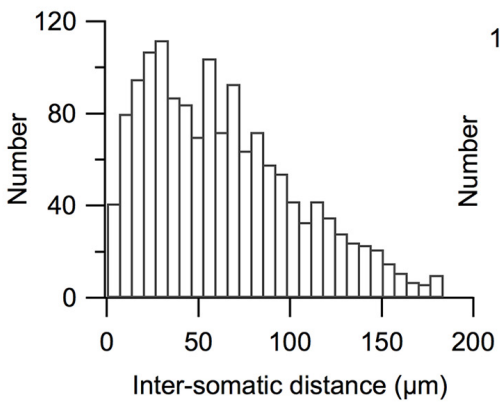

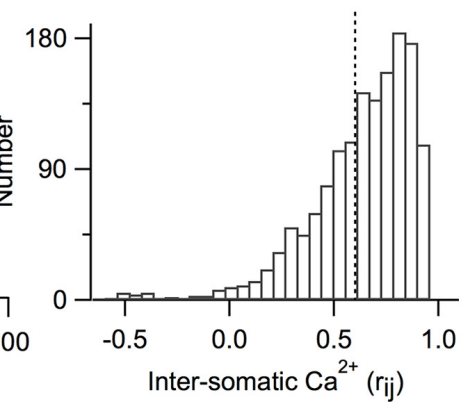

Figure 2. $\mathrm{Ca}^{2+}$ transients in GCAMP6s-expressing stellate cells during rhythmic licking. A1, Top, Average two-photon image of the molecular layer during a licking session. Bottom, Ovals with numbers identify single stellate cell somata, which were traced with ImageJ software and then automatically scrutinized and numbered with MATLAB routines. $A \mathbf{2}$, Top, Electrical signal generated by licking episodes. Bottom, Average of the time-dependent $\Delta F / F_{0}$ traces for the 21 stellate cells outlined in $A 1$. The dotted line marks the zero $\Delta F / F_{0}$ level. $A 3$, Corresponding waterfall plot for individual stellate cells. $\boldsymbol{B}$, Schematics for the calculation of $r_{\mathrm{ij}}$ between $\mathrm{Ca}^{2+}$ responses of all combined neuron pairs and the corresponding $d_{\mathrm{ij}}$. $\boldsymbol{C}$, Histogram distribution of the distances of stellate cell pairs. $\boldsymbol{D}$, Histogram distribution of all soma-to-soma correlations in $\mathrm{Ca}^{2+}$ responses. The dotted line marks the mean value. A total of 1494 combined neuronal pairs were analyzed in 14 imaging runs from $n=4$ mice.

visually in the electrical recording and histograms of various parameters were constructed using standard algorithms. Jaw movements during bruxing or licking episodes were analyzed from video recordings by drawing a region of interest (ROI) under the jaw in the inferior edge of the closed mouth, corresponding to dark pixels from the background. When mice opened their jaws, the ROI was filled with bright pixels from the skin illuminated with the infrared light, increasing the intensity counts inside the ROI. To compare the amplitude of the jaw movements during licking and bruxing, a separate analysis was done for days when mice performed both behaviors in the same imaging session to have a common head and jaw position. A ROI was drawn in the inferior part of the jaw in the position of maximal aperture during licking. The mean gray value inside the ROI was measured during licking and bruxing episodes within each session. During licking, the time course of the jaw motility trace obtained with this approach closely followed the time course of the licking junction potential trace, thus validating the measurement.

To correct the two-photon images for movements in the horizontal plane, films produced from image sequences were stabilized using the Image Stabilizer plug-in for ImageJ (Schneider et al., 2012). Unlike these movements, which can easily be corrected, movements in the $z$ direction are difficult to deal with because cell bodies move in and out of the focal plane. Accordingly, image recordings were processed for analysis only if visual inspection showed that there was no movement in the $z$ direction. After correction for movement, average images were produced for each acquisition sequence and ROI manager tools (from ImageJ) were used to create binary masks for all somata in the field. These masks were used to define the ROIs for further analysis with custom written MATLAB (The MathWorks) algorithms.
Temporal traces were produced for each ROI defined by the binary mask to extract spatiotemporal correlations between $\mathrm{Ca}^{2+}$ signals. Background correction was done with ImageJ by subtracting the mean value of at least three non-cell subregions $(10 \times 10$ pixels $)$ from the image for each case. Responsive neurons were defined as those with a fluorescence time course that contained at least three consecutive data points exceeding three times the SD of the baseline fluorescence $\left(F_{0}\right)$. Fluorescence signals were then normalized over $F_{0}$ as $\Delta F / F_{0}$ over time. Calcium strength was defined as the integral $\left(\Delta F / F_{0}{ }^{*} s\right)$ of the traces over defined time periods.

For data obtained from stellate cells, we quantified the spatiotemporal correlation of the fluorescence signals as follows. After defining the responsive neurons ( $94 \%$ of the total number of identified stellate cells) for a single run, the distance between neuronal somata was calculated for all combinations (pairs) of responsive neurons and the Pearson's correlation coefficient $\left(r_{\mathrm{ij}}\right)$ was calculated for all corresponding pairs as schematized in Fig. $2 B$. To determine whether closer cells have more correlated $\mathrm{Ca}^{2+}$ responses than distant ones, we examined the overall correlation between $r_{\mathrm{ij}}$ values of all neuronal pairs and their corresponding distances by linear regression in IGOR (WaveMetrics). A significantly negative slope suggests that closer neurons show more correlated $\mathrm{Ca}^{2+}$ responses.

To analyze the stellate cells along or orthogonal to the PF orientation, we traced the orientation of the neurites from the average intensity image of the time-lapse stack using ImageJ. Parallel lines of stellate cells were seen clearly along this orientation. The cell positioning was then defined along or orthogonal to this orientation. The correlation between the $r_{\text {ij }}$ of $\mathrm{Ca}^{2+}$ responses and the distances of all paired stellate cells was calculated, either along or orthogonal to the orientation of the stellate cell 
neurites. The spatiotemporal correlation analysis was performed using MATLAB and linear regression fits of the pooled data were done in IGOR.

Experimental design and statistical analysis. Imaging data for this study were collected from six female mice kept under similar housing conditions according to the rules of our animal care facility. In the Results section, for each experimental parameter analyzed, we report the number of animals, the number of imaging runs, and the number of cells. For pooled data, we report the mean \pm SEM and perform statistical comparisons using $t$ tests in MATLAB. The resulting $t$ and $p$-values are reported. Analysis of correlations was performed using the linear regression fit routine of IGOR and the Pearson's coefficient returned by the fit routine $( \pm \mathrm{SD})$ is reported along with the calculated significance level. Results were considered significant at $p<0.05$.

\section{Results \\ $\mathrm{Ca}^{2+}$-dependent activity of cerebellar interneurons during rhythmic licking}

To study the activity of stellate and basket cells in vivo, we expressed the GECI protein GCaMP6s (Chen et al., 2013) in the cerebellar cortex of adult PV-Cre mice by stereotaxic injections of floxed AAV viral vectors (as detailed in the Materials and Methods). As reported recently (Astorga et al., 2015), this yields specific expression in MLIs. GCaMP6s was preferred to GCaMP6f because it provides a more precise image of the resting cells, thus facilitating the analysis of individual MLI activity in the present work. Because of the presence of high PV concentrations in MLIs (Collin et al., 2005), somatic calcium signals are slow and need to be integrated over time to become detectable (Franconville et al., 2011). Therefore, GCaMP6s is well suited to report the calcium activity in these neurons, as already reported for PV-positive interneurons in other brain regions (Chen et al., 2013). Imaging was performed in the posterior part of Crus II, from fields of $150-200 \times 80-100 \mu \mathrm{m}$ in size at depths of $20-200 \mu \mathrm{m}$ from the surface of the cerebellar cortex using two-photon laser scanning microscopy (Fig. 1A). In the molecular layer, a large number $(\sim 20)$ of stellate cell somata were monitored simultaneously (Fig. 1B). Image sizes and acquisition rates $(4-7 \mathrm{~Hz})$ were adjusted so that this number of individual cells could be examined during active behavior. At higher magnification, nuclear exclusion of GCaMP6s fluorescence and preferential orientation of stellate cell neurites along the parasagittal direction were visualized clearly (Fig. 1C). Near the PC layer, at the bottom of the molecular layer, GCaMP6s expression in basket cell somata and neurites was also well defined. PC somata did not express GCaMP6s and were surrounded by basket cell axons and basket terminals (Fig. $1 D$ ). An analysis of the results obtained for basket cells near the PC layer is presented below (see Fig. 8). The results presented next concern the more superficially located stellate cells.

To investigate the spatiotemporal pattern of activity in stellate cells during oromotor behaviors, we first characterized $\mathrm{Ca}^{2+}$ signals from these neurons in Crus II while mice performed rhythmic licking. As detailed in the Materials and Methods, water-restricted animals were habituated to the head-fixed condition in our two-photon imaging setup before recording sessions started. During imaging sessions, mice had access to water in a valve-controlled manner and performed rhythmic licking episodes. The valve was opened for periods of 40-60 s while imaging was performed. The imaging runs were repeated at intervals of 1-5 min. Licking events were recorded via the electrical contact formed between the mouse tongue and the licking port (Fig. 1E). The contact periods ("licks") were short (Fig. 1F; mean duration: $48.2 \pm 3.1 \mathrm{~ms} ; 284$ events). Licks occurred in bursts and groups of bursts formed episodes (Fig. 1E). Bursts were defined as a series of licks with interlick intervals (ILIs) $<0.5$ $s$ (Fig. $1 E$, inset). Within a burst, ILI durations had an average of $140 \mathrm{~ms}$ (Fig. $1 G$ ) and each burst contained, on average, 6.7 licks (Fig. $1 H$ ). Bursts were separated by rest periods ranging from 0.5-8 s (Fig. 1I) and, for the analysis presented here, we defined lick episodes as groups of bursts separated by $<2 \mathrm{~s}$.

In all experiments, licking episodes were accompanied by changes in the $\mathrm{Ca}^{2+}$-dependent GCaMP6s fluorescence. An example of the electrically monitored licking behavior and of the simultaneous $\mathrm{Ca}^{2+}$ activity observed in stellate cells is presented in Figure $2 \mathrm{~A}$. All of the stellate cells in the imaged field ( 22 somata in this case; Fig. 2A1) displayed $\mathrm{Ca}^{2+}$ signals during licking episodes (individual traces in Fig. 2A3). As shown by the licking signal and the average $\mathrm{Ca}^{2+}$ signal (red and green traces in Fig. $2 A 2$, respectively), $\mathrm{Ca}^{2+}$ activity starts near the onset of each licking episode, rises during the entire episode, and relaxes slowly toward baseline after the end of each episode. Synchronization among neighboring cells is evident in the waterfall plot of individual $\Delta F / F_{0}$ traces (Fig. 2A3). To quantify the degree of synchronization for all combinations of cell pairs labeled $(i, j)$, we measured intersomatic distances $\left(d_{\mathrm{ij}}\right)$ and calculated the Pearson's correlation coefficient $\left(r_{\mathrm{ij}}\right)$ of the $\mathrm{Ca}^{2+}$ signals for all combinations, as schematized in Figure $2 B$. Group results for 14 recordings $(n=4$ mice) are presented in Figure 2, $C$ and $D$. Although $d_{\mathrm{ij}}$ values ranged from $10-190 \mu \mathrm{m}$, reflecting the size of our field of view (Fig. 2C), we found a high degree of temporal correlation for $\mathrm{Ca}^{2+}$ signals (mean $r_{\mathrm{ij}}=0.602 \pm 0.006$; Fig. $2 D$ ), suggesting widespread and homogeneous stellate cell activation during licking in the range of distances investigated.

\section{Temporal correlation between $\mathrm{Ca}^{2+}$ rises and the onset of licking episode}

Next, we compared the onset time of the licking episodes, defined as the first downward deflection of the licking trace, and that of the corresponding $\mathrm{Ca}^{2+}$ signal, defined as the first point of the $\mathrm{Ca}^{2+}$ trace deviating from the mean by $>3$ times the SD of the pre-episode period (Fig. 3A). Values for the relative onset of the $\mathrm{Ca}^{2+}$ signal versus the licking trace ranged from -133 to 580 $\mathrm{ms}$, with an average of $183.6 \mathrm{~ms}$ (Fig. $3 B$ ), suggesting that, on average, licking onset precedes the onset of the $\mathrm{Ca}^{2+}$ signal. For this analysis, well separated bursts displaying a flat baseline were selected. Surprisingly, we found that the delay depended on the number of the licks during the first burst of the episode. Figure $3 A 1$ shows an example of a burst comprising two licks in which the onset time of the corresponding $\mathrm{Ca}^{2+}$ signal has a negative value. In contrast, in Figure $3 A 2$, for a burst containing a larger number of licks (here, 11 licks), the onset of the $\mathrm{Ca}^{2+}$ signal displayed a significant delay compared with the licking onset. Group results indicate close-to-zero temporal difference between lick and $\mathrm{Ca}^{2+}$ for bursts with small lick numbers, but significant delays for $\mathrm{Ca}^{2+}$ signals evoked by bursts with large lick numbers (Fig. 3C). An exponential fit shows an asymptote of $364 \mathrm{~ms}$ for long licking bursts (Fig. $3 \mathrm{C}$ ). These results suggest that, in general, stellate cell $\mathrm{Ca}^{2+}$ signals tend to follow licking. In addition, they reveal an unexpected correlation between $\mathrm{Ca}^{2+}$ signal onset and number of licks during a licking episode. Accordingly, for very short bursts (one or two licks), some recordings show the opposite temporal relation, licking then $\mathrm{Ca}^{2+}$ sequence (as exemplified in Fig. 3A1), and, on average, we found no significant time difference between licking and $\mathrm{Ca}^{2+}$ onset for the short bursts (Fig. 3C, first bin). The exact reason for the difference of delays depending on lick number is unclear. However, it may be speculated that short licking episodes (one or two licks) aim at 
A1

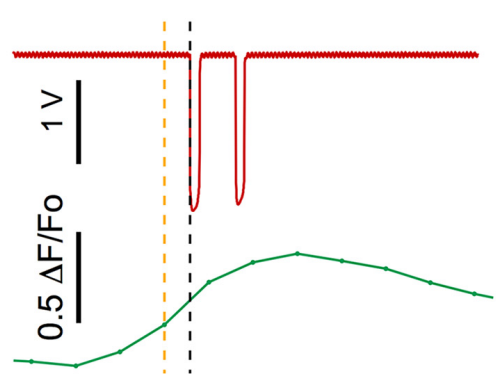

A2

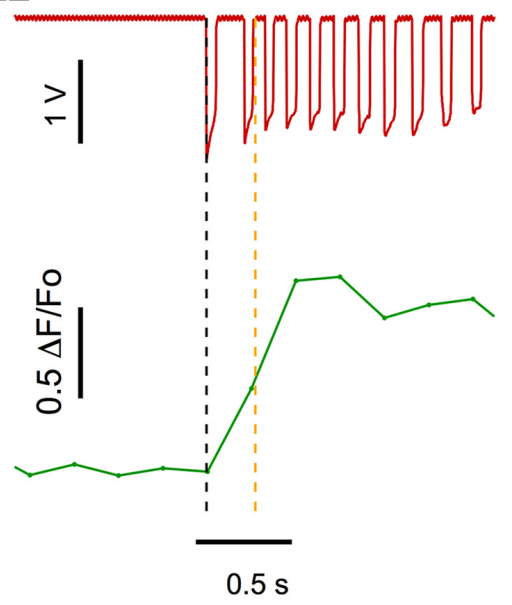

B

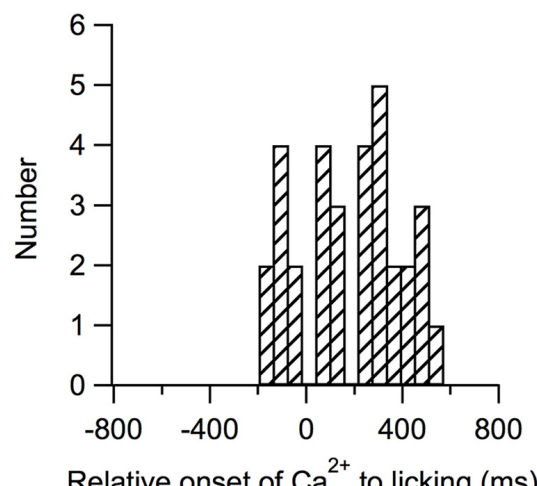

C

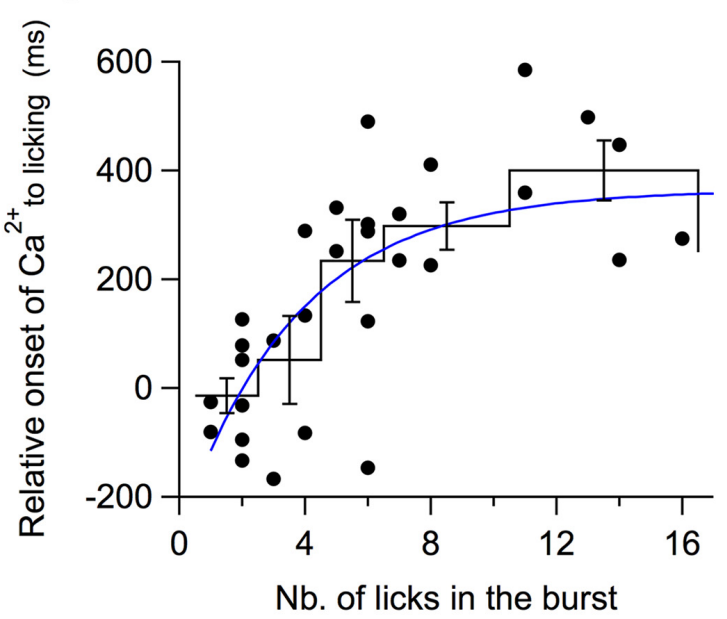

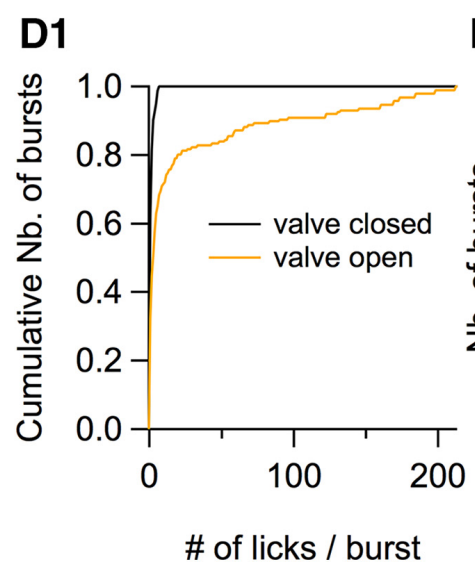

D2

D3

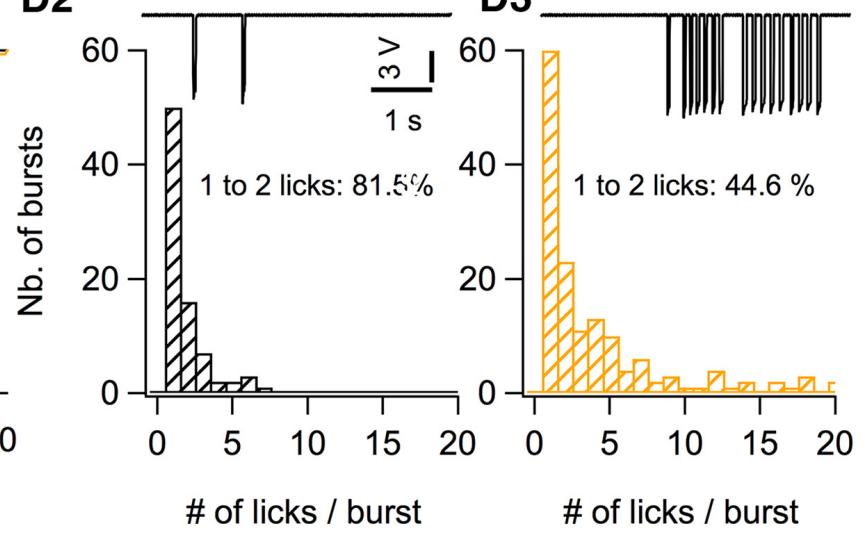

Figure 3. Temporal correlation between licking behavior and $\mathrm{Ca}^{2+}$ rises. $\mathbf{A 1}, \mathbf{A 2}$, Two examples of lick bursts (red) and of the corresponding averaged $\Delta F / F_{0}$ traces (green) illustrate the analysis done to determine the relative onset of the $\mathrm{Ca}^{2+}$ signal with respect to the licking trace. The black dotted line marks the onset time for licking, determined as the first data point that deviates from the baseline by $>3$ times the SD. The green trace shows the $\mathrm{Ca}^{2+}$ signal corresponding to a time window ranging from $-1 \mathrm{~s}$ to $1.5 \mathrm{~s}$ with respect to licking onset. The $\mathrm{Ca}^{2+}$ onset time (orange dotted line) was determined as the first data point deviating by $>3$ times the SD from the $\mathrm{Ca}^{2+}$ trace baseline. In one case, the $\mathrm{Ca}^{2+}$ trace precedes licking onset (A1) and, in the other example, the $\mathrm{Ca}^{2+}$ trace lags after licking onset (A2). $\boldsymbol{B}$, Distribution of the relative onset of the $\mathrm{Ca}^{2+}$ traces versus the licking traces, with a mean value of $183.6 \pm 37.4 \mathrm{~ms}(n=32 \mathrm{bursts}$ from $8 \mathrm{imaging}$ sections, $n=5$ animals). C, Relationship between the $\mathrm{Ca}^{2+}$ onset time and the number of licks in the burst. The black circles show individual data points; the continuous black profile shows means \pm SEM of binned data; blue curve shows the fit of the data points by an exponential function with a lick number parameter value of 3.7 licks and a saturation at $364 \mathrm{~ms}$. D, Comparison of the distribution of number of licks per burst when a valve controlling water delivery is closed (black cumulative histogram in D1; corresponding expanded histogram in D2) and when the valve is open (yellow plot in D1; corresponding histogram in D3). The traces in D2 and D3 show examples of licking recording when the valve is closed (D2) or open (D3). The histograms correspond to data pooled from 9 licking sessions from $n=3$ mice.

checking the presence of water, while long licking episodes (more than two licks) aim at liquid intake. Therefore, the difference of delays may be linked to the difference of context between the short and long licking episodes.
To test this hypothesis, we compared the licking activity depending on whether a water-supplying valve was open or closed. The mean number of licks in a burst strongly increased from $1.8 \pm 0.1$ when the valve was closed to $19.0 \pm 2.3$ when the valve 
was open $(t=6.1, p<0.0001)$. Conversely, surprisingly, interburst intervals were similar when the valve was closed $(2.64 \pm$ $0.24 \mathrm{~s})$ and when it was open $(2.41 \pm 0.35 \mathrm{~s})(t=0.4, p>0.5)$. A closer analysis revealed that the histogram of lick numbers/burst had a single component when the valve was closed, with very low lick numbers (mostly one or two licks/burst; Fig. 3D1,D2, black), whereas, when the valve was open, a second component appeared with many more licks/burst (Fig. 3D1, D3, yellow). The percentage of bursts with one or two licks/burst decreased from $81 \%$ when the valve was closed to $44 \%$ when the valve was open (Fig. $3 D 2, D 3)$. These results confirm the coexistence of two separate kinds of bursts when the valve is open. They further suggest that the long bursts are dedicated to immediate water intake, whereas the short bursts are linked more indirectly to water intake and could be motivated by the planning of future water intake.

\section{Stellate cell activity during bruxing}

The above results show that $\mathrm{Ca}^{2+}$ rises occur in stellate cells during licking episodes. In addition, we noticed in several recording sessions that these neurons displayed $\mathrm{Ca}^{2+}$ transients in the absence of licking. We hypothesized that such signals could be linked to periods of motor activity because, in the absence of licking, mice were often engaged in tooth sharpening (also known as bruxing), a grooming behavior that involved repetitive movements of the jaw in episodes lasting $\sim 1-3 \mathrm{~min}$. It has been shown that both chewing and tooth sharpening involve rhythmic bursts of activity in the anterior temporalis muscle mainly during jaw closure and opening in the masticatory and bruxing cycles, respectively (Byrd, 1997). Because a modulatory role for the cerebellum in motor control of this type of orofacial behavior has been advanced (Moore et al., 2014), we postulated that the observed $\mathrm{Ca}^{2+}$ transients are correlated with bruxing. To test this possibility, we analyzed video recordings of mice during $\mathrm{Ca}^{2+}$ imaging sessions. Jaw motility traces were generated from the video recordings (see Materials and Methods) and were used to explore the correlation between this motor behavior and stellate cell activity.

As shown in Figure 4A, resting periods when no jaw activity was registered displayed very low $\mathrm{Ca}^{2+}$ signals. Conversely, periods exhibiting repetitive jaw movements (deflections in Fig. 4B2, top) showed concerted $\mathrm{Ca}^{2+}$ rises with variable peak amplitudes (average trace in Fig. 4B2, bottom). As during licking, a waterfall display revealed a high degree of correlation between individual stellate cells $\mathrm{Ca}^{2+}$ signals during bruxing (Fig. 4B3). In contrast to licking, however, it was difficult to identify a clear temporal correlation between bruxing episodes and the corresponding $\mathrm{Ca}^{2+}$ signals (Fig. 4B2). Nevertheless, it was possible to separate recording periods clearly into "bruxing" and "control" episodes according to the jaw motion integral (Fig. 4C; threshold value for jaw motion integral: $4 \times 10^{3}$ ). Using this classification, group results revealed larger $\mathrm{Ca}^{2+}$ signal integrals (approximately one order of magnitude of difference; Fig. 4D) and higher numbers of $\mathrm{Ca}^{2+}$ transients (Fig. $4 E$ ) during bruxing than in controls, confirming a link between neuronal activity and bruxing.

\section{Comparison of stellate cells $\mathrm{Ca}^{2+}$ activity during licking, bruxing, and whisking}

During these experiments, mice often whisked. Whisking occurred irrespective of whether mice were engaged in jaw movements or not. To investigate possible links between $\mathrm{Ca}^{2+}$ rises observed during high motility periods and whisking-evoked signaling, we analyzed the fluorescence traces for episodes of low jaw motility, during which video recordings showed active whisking.
We found that, contrary to both licking and bruxing, these episodes were not accompanied by detectable changes in stellate cell fluorescence (Fig. $5 A, B$ ). Because our results were derived from the posterior part of Crus II, the lack of $\mathrm{Ca}^{2+}$ activity during whisking in the present work is consistent with previous reports indicating that whisking-related inputs to PCs are restricted to Crus I and very rarely to the anterior part of Crus II (Bosman et al., 2010; Chen et al., 2016).

To compare the strength of the $\mathrm{Ca}^{2+}$ rises during whisking, licking, and bruxing, the $\mathrm{Ca}^{2+}$ integral was computed for these behaviors. Pooled data show that the signals were weak for whisking compared with both licking and bruxing. Bruxing episodes were actually accompanied by somewhat stronger $\mathrm{Ca}^{2+}$ integrals than licking episodes (Fig. 5 C). Overall, in the stellate cell network of the Crus II region, bruxing and licking were accompanied by potent correlated $\mathrm{Ca}^{2+}$ signals whereas whisking was not.

Could licking and bruxing reflect a common underlying motor behavior possibly linked to jaw movement? This seems unlikely given the marked differences in the patterns of $\mathrm{Ca}^{2+}$ responses for the two types of behavior (cf. Figs. 2, 4). In addition, camera-registered optical jaw movement signals during bruxing and licking were strikingly different (Fig. 5D). Licking gave rise to high-amplitude, fast, quickly reversible jaw movements that were time locked with tongue-generated electrical signals, whereas bruxing was accompanied by low-amplitude, stepwise jaw movements (Fig. 5D). Plots of jaw movement amplitudes revealed nonoverlapping amplitude histograms between licking and bruxing episodes (Fig. 5E). This contrasts with the results of Figure $5 C$ showing slightly larger stellate cell $\mathrm{Ca}^{2+}$ signals during bruxing compared with licking. These results, together with the lack of strict correlation between stellate cell activity and jaw movement during bruxing, argue against the hypothesis that stellate cell activity reports jaw movement in a direct way. Further differences between the patterns of stellate cell activity associated with licking and bruxing are described next.

\section{Spatial organization of stellate cell activity during licking}

Given the above evidence for correlated stellate cell activity during orofacial motor behaviors, we next investigated whether the $\mathrm{Ca}^{2+}$ signals display any spatial orientation in the imaged field. The cerebellar cortex is organized in a highly regular manner, with PFs running orthogonal to stellate cell dendrites. If the correlations are driven by common PF excitation, then $\mathrm{Ca}^{2+}$ rises should be homogeneous along the PF axis and variable along the orthogonal direction. Therefore, we plotted correlations ( $r_{\mathrm{ij}}$ values) of $\mathrm{Ca}^{2+}$ signals of all the stellate cell pairs visualized as a function of their distance in the field both along the direction of the PFs and in the orthogonal direction. Each field of $200 \times 100 \mu \mathrm{m}$ contained up to 25 MLIs that exhibited GCaMP6 staining in their soma and dendrites. Dendritic staining displayed a clear striated pattern along the sagittal direction and therefore provided a reference for this direction (which is orthogonal to that of the PFs; Fig. $6 A 1, B 1)$.

We first performed this analysis for the $\mathrm{Ca}^{2}$ signals observed during licking. In accordance with the concerted activity of these signals in the example of Figure $2 A, r_{i j}$ values were generally high for neuron pairs taken along the orientation of stellate cell neurites (mean \pm SEM: $0.55 \pm 0.02$; Fig. $6 A 1, A 2$ ), as well as orthogonally to such neurites, after the orientation of the PFs $(0.58 \pm$ 0.02 ; Fig. $6 B 1, B 2)$. However, there was a negative correlation between $r_{\mathrm{ij}}$ values and distance $d_{\mathrm{ij}}$ along the sagittal orientation after the orientation of stellate cell neurites (slope of the linear regression fit: $-0.0023 \pm 0.0006, n=130 ; t=3.85, p<0.001$; 
A1

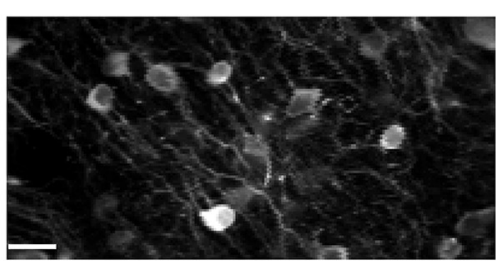

\section{$20 \mu \mathrm{m}$}

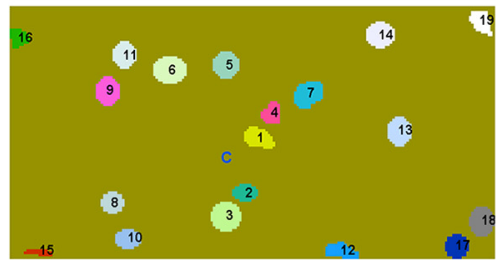

B1

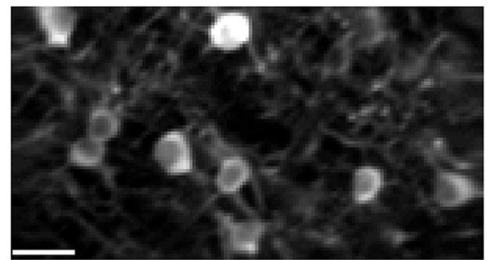

\section{$20 \mu \mathrm{m}$}

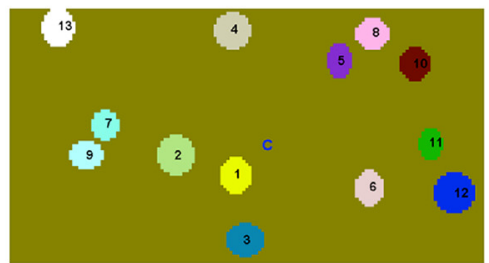

Jaw motion traces

A2

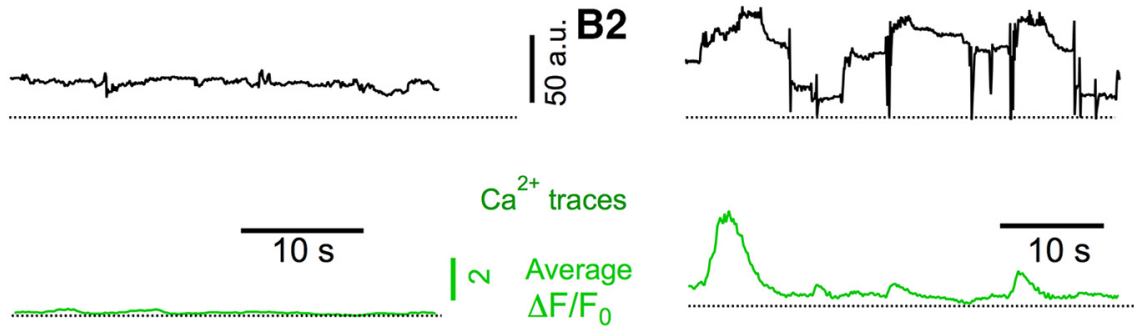

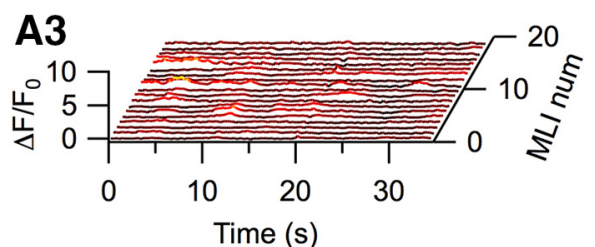

C

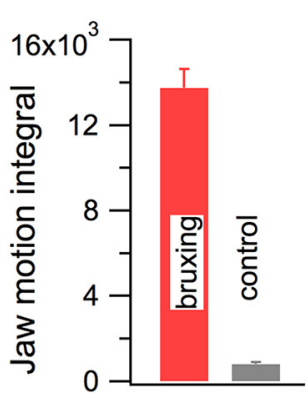

B3

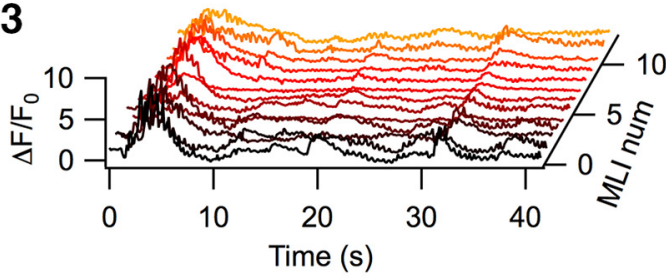

E

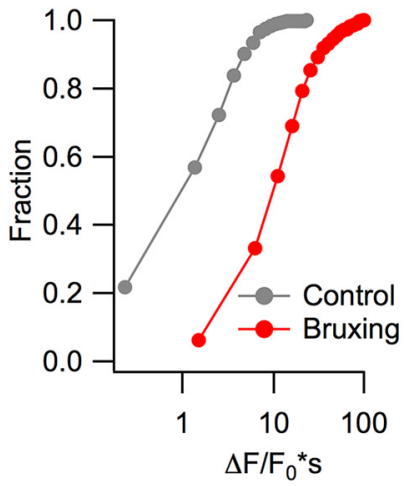

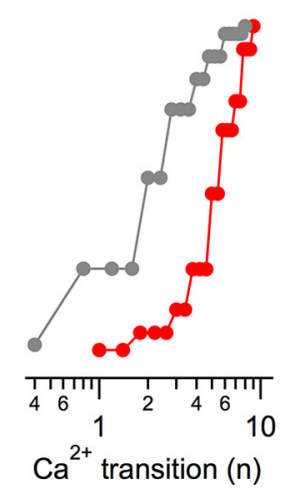

Figure 4. Stellate cells $\mathrm{Ca}^{2+}$ signals during bruxing. A1, B1, GCAMP6-expressing stellate cells imaged by two- photon microscopy (top) and the ROls used for analysis (bottom). $A 2, B 2$, Representative traces for jaw motion (black) and $\mathrm{Ca}^{2+}$ (green) for periods of low and high jaw motility. Jaw motility traces were extracted from infrared video imaging and the $\mathrm{Ca}^{2+}$ corresponds to the average of 19 individual stellate cells in $A 2$ and 13 in $B 2 . A 3, B 3$, Corresponding waterfall plots for individual stellate cells. C, Comparison of the jaw motion integral in periods of high and low motility shows a marked difference between the two groups $(t=10.2 ; p<0.0001) . \boldsymbol{D}, \mathrm{Ca}^{2+}$ strength is significantly higher for periods of high motility than during low-motility sessions $(t=13.4 ; p<0.0001)$. $\boldsymbol{E}$, Difference between the two conditions is also highly significant when the number of $\mathrm{Ca}^{2+}$ transitions is compared $(t=7.3 ; p<0.0001)$. Data for $\boldsymbol{C}-\boldsymbol{E}$ are from three mice, 788 stellate cells from 50 imaging runs during high-motility periods, and 364 stellate cells from 27 imaging runs during low-motility periods.

Fig. 6A2), whereas there was no dependence of $r_{\mathrm{ij}}$ values on $d_{\mathrm{ij}}$ for signals along the PF orientation; that is, orthogonal to stellate cell neurites $(-0.0002 \pm 0.0006 ; n=125 ; t=0.357, p>0.5$; Fig. $6 B 2)$. Therefore, the dependence of intersomatic $\mathrm{Ca}^{2+}$ correlations on distance differs significantly for the two orientations (Fig. 6C).
These results indicate that stellate cell $\mathrm{Ca}^{2+}$ rises during licking are organized along the PF axis and suggest an activity pattern originating at the level of PFs. However, before accepting this conclusion, alternative interpretations were examined. We envisaged first that, during selection of stellate cells for orientation analysis, a bias may have occurred so that cells with weaker signals 
A

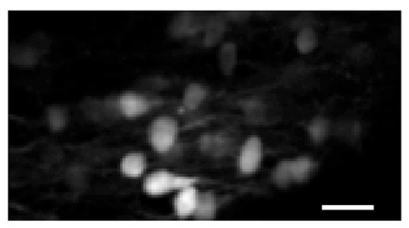

$20 \mu \mathrm{m}$

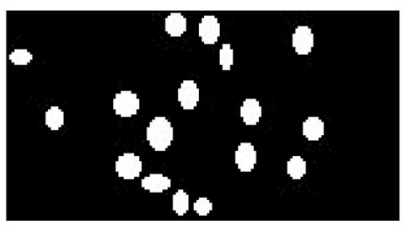

C

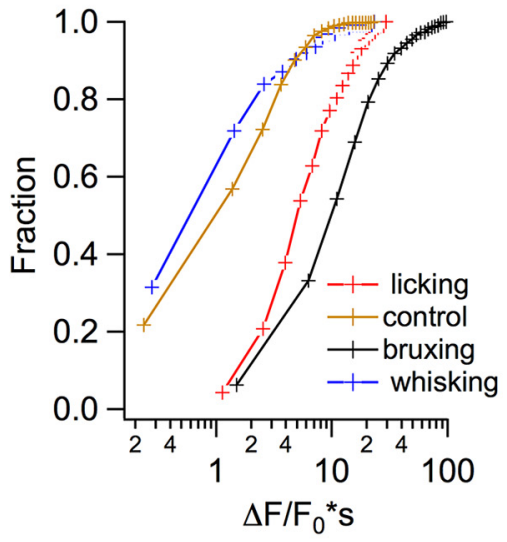

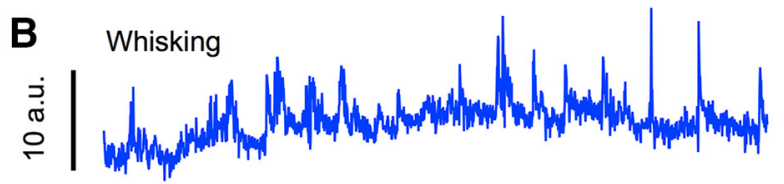
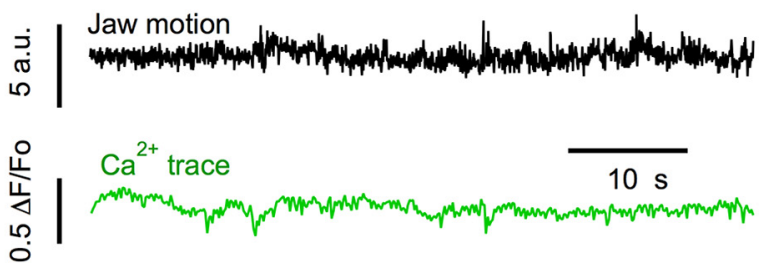

D

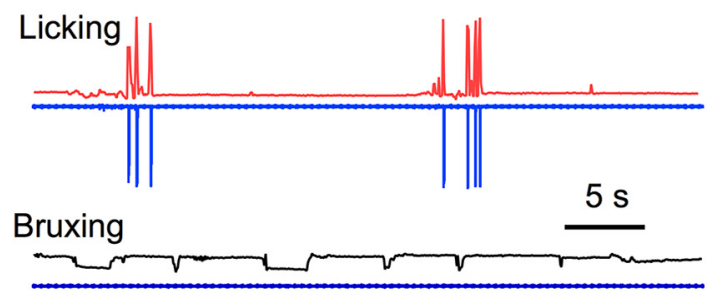

E

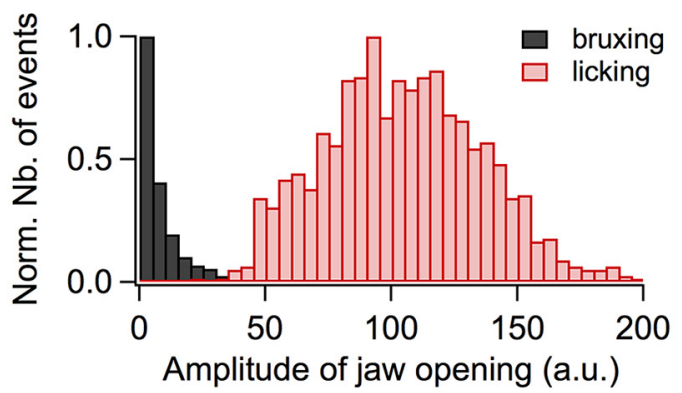

Figure 5. Stellate cells $\mathrm{Ca}^{2+}$ signals are absent during whisking. $\boldsymbol{A}$, Two-photon images of GCAMP6-expressing stellate cells (top) and the R0Is used for analysis (bottom). $\boldsymbol{B}$, Representative traces for whisker movement (blue), jaw motion (black), and $\mathrm{Ca}^{2+}$ (green) during a period of low jaw motility and active whisking. Jaw motility and whisking traces were extracted from infrared video imaging as detailed in the Materials and Methods and the $\mathrm{Ca}^{2+}$ corresponds to the average of 16 stellate cells. $C$, Ca ${ }^{2+}$ strength is significantly lower for whisking than for either bruxing $(t=7.6, p<0.0001)$ or licking $(t=8.1, p<0.0001)$, whereas bruxing periods have a significantly higher $\mathrm{Ca}^{2+}$ strength than licking episodes $(t=5.3, p<0.0001)$. The data were p0oled from 788 stellate cells from 50 imaging runs, $n=3$ mice for bruxing episodes; 188 stellate cells from 15 imaging runs, $n=4$ mice for licking episodes; and 124 stellate cells from 11 imaging runs, $n=$ 4 mice for whisking episodes. The control trace depicts the data for low jaw motility runs, as in Figure 4D. D, Examples of jaw motility and licking signals for a recording session in which the mouse performed rhythmic licking (top) and for a different session for the same mouse during bruxing (bottom). The electrical signals for licking are shown in blue. Note that the signal is flat for the bruxing episode. The corresponding jaw motility traces are shown in red (licking; note the temporal correspondence with the electrical licking trace) and black (bruxing). Vertical scales are the same for top and bottom. $\boldsymbol{E}$, Comparison of the amplitude distributions of the jaw movement during licking and bruxing. Data were pooled form 7 recording sessions ( $n=4$ mice). The jaw movement amplitude was quantified by calculating the difference between the maximum and minimum gray values inside a ROI drawn in the inferior part of the jaw, as detailed in the Materials and Methods.

were included in the analysis of the "along" orientation. However, cumulative plots of peak $\mathrm{Ca}^{2+}$ rises showed no dependence of the calcium strength on orientation (Fig. 6D). Second, we envisaged the possibility that, due to the geometry of the system, shorter distances were investigated along the PF axis, in which case the difference of Figure $6 C$ could have been erroneous. The orientation of MLI-associated striations in the field of view varied somewhat depending on the orientation of the animal head during imaging. However, overall, the range of soma-to-soma distances investigated along the PF direction was slightly larger than in the orthogonal direction (Fig. 6A1,B1). Under these conditions, geometric restrictions tend to emphasize correlations along the PF direction. Another possible artifact could have been that a preferential orientation of the preparation in relation with $x-y$ scanning might have led to a systematic time bias. However, the orientation of stellate cell neurites was usually diagonal with respect to scanning directions, as illustrated in Figures 1, 4, and 6. In this situation, artifacts due to scanning delays should be negligible. In summary, neither stellate cell selection nor imaging window orientation can explain the results of Figure 6, so we conclude that licking is indeed driven by PF activity in Crus II. Moreover, the negative correlation between $\mathrm{Ca}^{2+}$ signals and soma-to-soma distance away from PFs suggests that PF activity is not homogeneous, but rather follows a pattern in which neighboring PFs tend to be synchronized. This observation is consistent with previous work showing patch-like activity in Crus II using intrinsic imaging in large fields covering an entire folium (Cramer et al., 2013).

Lack of spatial organization of MLI activity during bruxing We next compared the temporal and spatial patterns of stellate cell activities for bruxing and licking. The histogram of $r_{\mathrm{ij}}$ values for bruxing (Fig. 7A2) had a shape similar to that obtained for licking (cf. Figs. 2D, 7A2), with respective mean values of $0.537 \pm$ 0.004 and $0.602 \pm 0.006$. This indicates a high level of correlated neuronal activity for the two types of behaviors. However, there was little dependence of $r_{\mathrm{ij}}$ values of $\mathrm{Ca}^{2+}$ signals versus somato-soma distance during bruxing either along stellate cell neurites (Fig. $7 B 1, B 2$ ) or in the orthogonal direction (Fig. $7 C 1, C 2$ ), so a comparison of the results along the two directions did not reveal 
A1 Along stellate cell neurites

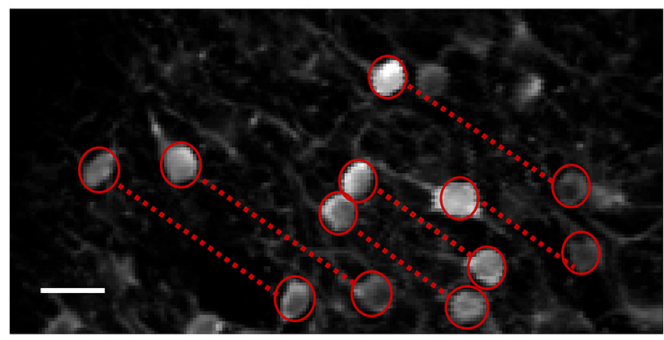

$20 \mu \mathrm{m}$

A2

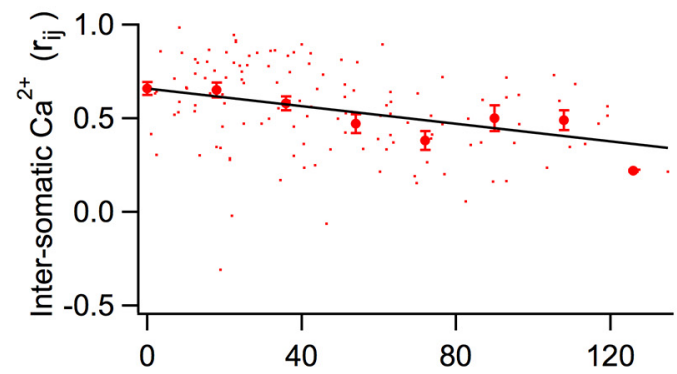

Inter-somatic distance $(\mu \mathrm{m})$

\section{C}

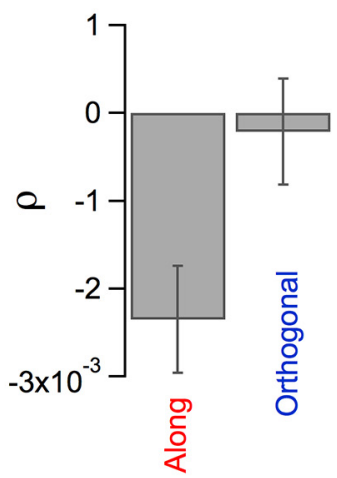

B1 Orthogonal to stellate cell neurites

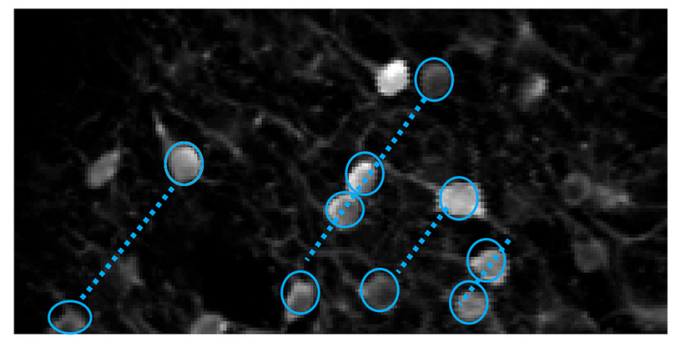

B2

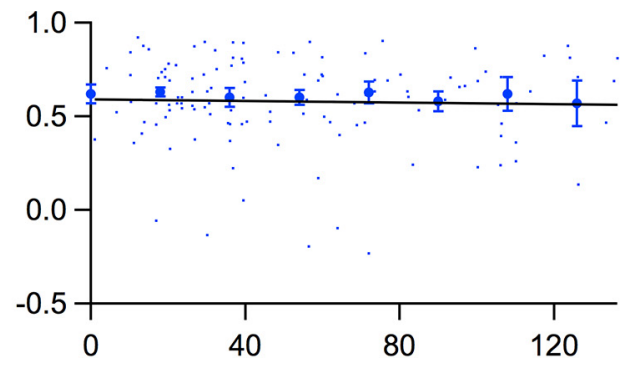

Inter-somatic distance $(\mu \mathrm{m})$

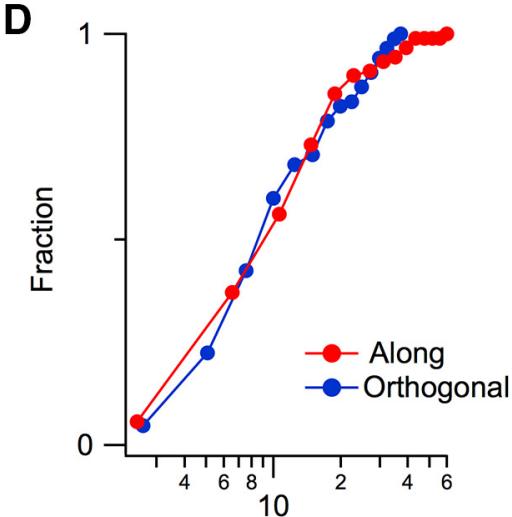

$\Delta \mathrm{F} / \mathrm{F}_{0}{ }^{*} \mathrm{~S}$

Figure 6. Spatial dependence of somatic $\mathrm{Ca}^{2+}$ correlations during licking. $\mathbf{A 1}$, Two-photon image in which individual stellate cell somata are marked with red circles and dotted lines join somata oriented along the axis of stellate cell neurites. A2, Red dots show individual $r_{\mathrm{ij}}$ values plotted against soma-to-soma distances. Red filled circles correspond to the mean \pm SEM for $18 \mu \mathrm{m}$ bins running over the whole range of distances. The black line shows the fit of the data by a linear function that yields a significant negative correlation with a slope of $-0.0023 \pm 0.0006$ ( $t=3.8, p<$ $0.001 ; 130$ stellate cell pairs from 13 imaging runs, $n=4$ mice). $B 1, B 2$, Similar analysis of the same data pool for stellate cells oriented orthogonally to the neurites. In this case, the fit of the data by a linear regression yields a slope value of $-0.0002 \pm 0.0006$ ( $t=0.36, p>0.5 ; 125$ stellate cell pairs from 15 imaging runs, $n=4$ mice), indicating that there is no significant dependence of the correlation on distance. $C$, Pooled results for the dependence of correlation of the $\mathrm{Ca}^{2+}$ responses on the distance for the two orientations. $\boldsymbol{D}$, No difference was found for the $\mathrm{Ca}^{2+}$ signal integral when stellate cells were compared in the two orientations ( $t=0.49 ; p>0.5 ; 85$ and 81 stellate cells from 13 and 15 imaging runs, respectively; $n=4$ mice).

any differences (Fig. $7 D, E$ ). This suggests that, whereas licking is driven by PF activity, bruxing is independent of the spatial organization of the PF system.

\section{Basket cell activity during licking and bruxing}

Although all interneurons of the molecular layer of the cerebellar cortex are often considered as a single neuronal population (Jörntell et al., 2010), interneurons vary according to their position in the molecular layer regarding morphology (Palay and Chan-Palay, 1974), intrinsic electrical properties, and characteristics of excitatory inputs (Bao et al., 2010). Furthermore, the influence exerted on target PCs differs for interneurons, which synapse mostly on PC dendrites (stellate cells), and for interneu- rons, with somata located close to the PC layer, which make highly stereotyped axonal projections or "baskets" on PC somata (basket cells; Vincent and Marty, 1996). In our calcium-imaging experiments, it was possible to select basket cells by choosing an imaging plane just above the PC layer. With this approach, we followed calcium-dependent activity of basket cell somata during both rhythmic licking and bruxing.

We found that $\mathrm{Ca}^{2+}$ signals were linked to rhythmic licking in basket cell somata (Fig. 8A1,A2). The $\mathrm{Ca}^{2+}$ signals for the basket cells in the imaged field were correlated, with a mean $r_{\mathrm{ij}}$ value of $0.58 \pm 0.01$ (749 basket cell pairs from 5 imaging runs; $n=4$ mice). This level of correlation is comparable to that obtained for stellate cells $(t=1.75, p=0.1)$. On average, the temporal relation 


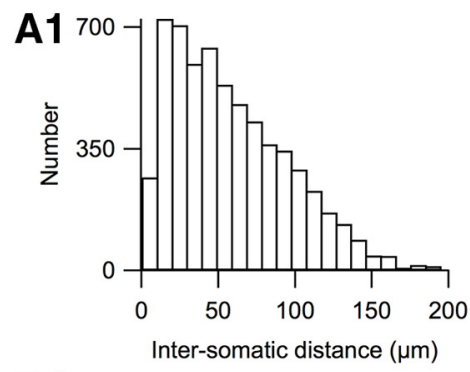

B1

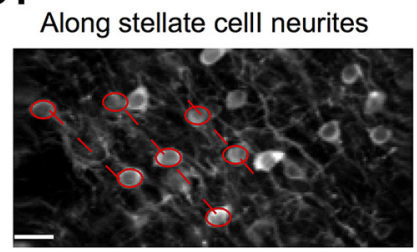

$20 \mu \mathrm{m}$

C1

Orthogonal to stellate cell neurites

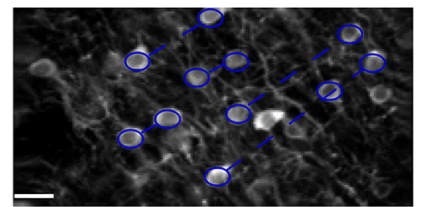

$20 \mu \mathrm{m}$
A2

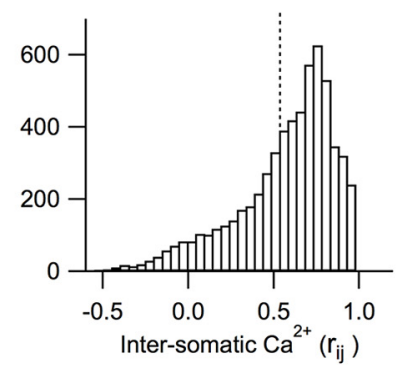

B2

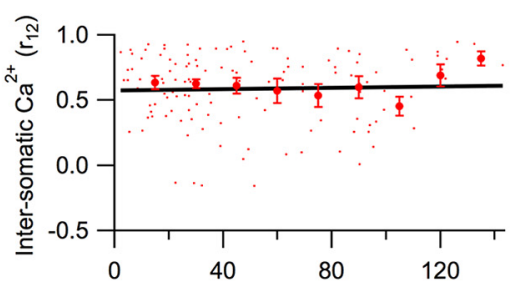

C2

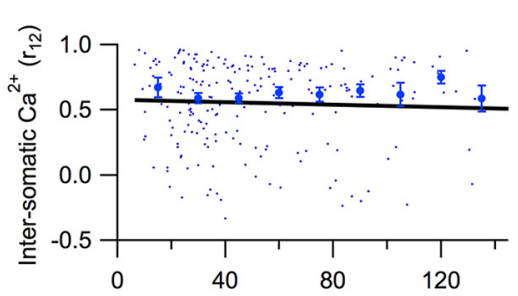

Inter-somatic distance $(\mu \mathrm{m})$
D

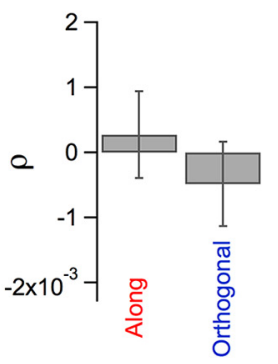

E

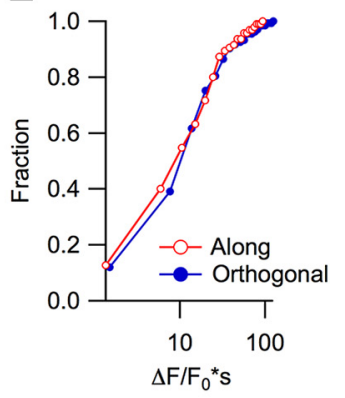

Figure 7. Spatial correlation analysis for stellate cells $\mathrm{Ca}^{2+}$ activities during bruxing. A1, Histogram distribution of the distances of all combined stellate cell pairs studied during bruxing. A2, Histogram distribution of all soma-to-soma correlations in $\mathrm{Ca}^{2+}$ responses (6118 pairs from 50 imaging runs, $n=3$ mice). The dotted line marks the mean value. B1, Two-photon image with individual stellate cell somata marked by red circles and dotted lines joining somata oriented along the axis of the stellate cell neurites. B2, Red dots show individual $r_{\mathrm{ij}}$ values plotted against soma-to-soma distances. Red filled circles indicate mean \pm SEM as in Figure 6 . The fit of the data by a linear function (black line) indicates no dependence of the $r_{\mathrm{ij}}$ values on distance (slope $=$ $0.0002 \pm 0.006 ; p>0.05 ; n=129$ stellate cell pairs from 25 imaging runs, $n=2$ mice). C1, C2, Similar analysis of the same data for stellate cells oriented orthogonal to the neurites. The linear regression yields a slope of $-0.0004 \pm 0.0006$ ( $p>0.05 ; 224$ pairs from 25 imaging runs). $\boldsymbol{D}$, Pooled results showing a lack of correlation of $\mathrm{Ca}^{2+}$ responses on distance for the two orientations. $E$, No difference was found between the stellate cells along and orthogonal to the neurites axis in terms of the $\mathrm{Ca}^{2+}$ signal integral $(t=0.7 ; p=0.5)$.

of $\mathrm{Ca}^{2+}$ signal onset to licking onset was also similar to that found for stellate cells (Fig. 8A3). During bruxing episodes, basket cells were active and their $\mathrm{Ca}^{2+}$ signals had a high level of coordination (Fig. 8B1,B2), with a mean $r_{\mathrm{ij}}$ value of $0.549 \pm 0.06(2950$ basket cell pairs from 41 imaging runs; $n=4$ mice), not significantly different from that obtained for stellate cells $(t=1.84, p=$ $0.07)$. In addition, the strength of the $\mathrm{Ca}^{2+}$ rises was similar to that of stellate cells (Fig. 8B3). These results indicate that stellate and basket cell have similar calcium signaling both during licking and bruxing.

\section{Discussion}

We provide here direct evidence for a strong activation of MLIs in mice performing oromotor tasks. These results add support to the general notion that MLI-mediated inhibition intervenes in the performance and/or learning of motor tasks. The lines of evidence contributing to this notion are multiple. First, genetic deletion of GABA-A receptors in PCs results in deficits in motor learning (Wulff et al., 2009; ten Brinke et al., 2015). Second, electrophysiological recordings (Jelitai et al., 2016) and $\mathrm{Ca}^{2+}$ imaging (Ozden et al., 2012) show that MLIs are active during locomotion and active whisking has been reported recently to engage changes in MLI spiking (Chen et al., 2017). Third, optogenetic studies of behaving mice reveal that it is possible to modulate/induce movement, not only by optical activation of PCs (Proville et al., 2014; Lee et al., 2015), but also by optical activation (Heiney et al., 2014) and inhibition of MLIs (Jelitai et al., 2016).
In the present study, we found that, during both licking and bruxing, groups of neighboring MLIs are engaged in highly coherent waves of synchronous neuronal activity. However, in several important aspects, the patterns of activity differ between the two types of tasks. Activity is more reproducible and synchronized for licking than for bruxing. For stellate cells, groups of active neruons are organized along the direction of PFs during licking, suggesting a drive by small bundles of PFs. In contrast, no spatial arrangement was recognizable during bruxing.

In broad agreement with the present work, a very recent study showed concerted MLI activity during licking (Gaffield and Christie, 2017). These two studies used different behavioral paradigms and therefore reveal different aspects of MLI involvement. Gaffield and Christie (2017) used a cued-licking task focused on the temporal correlation between isolated licks and $\mathrm{Ca}^{2+}$ signals, whereas we studied MLI activity during lick bursts, allowing us to uncover interesting temporal correlations between $\mathrm{Ca}^{2+}$ signal onset and lick parameters (Fig. 3), as detailed below. Furthermore, although both studies found widespread MLI activation during licking, our spatial correlation analysis revealed anisotropic stellate cell signals along the PF orientation (Fig. 6), suggesting that they are driven by PFs. An important difference between these two studies concerns MLI activity during nonlicking periods. We found that mice engaged in periods of bruxing, during which MLI activity was of comparable strength to that observed during rhythmic licking 


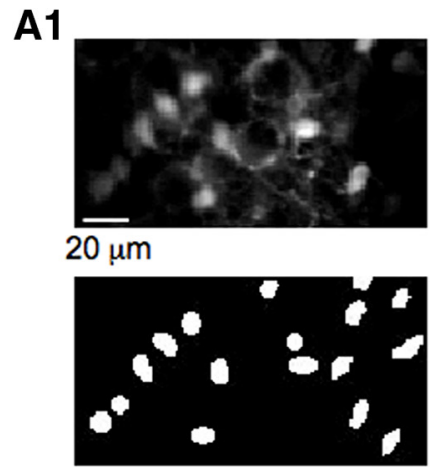

B1

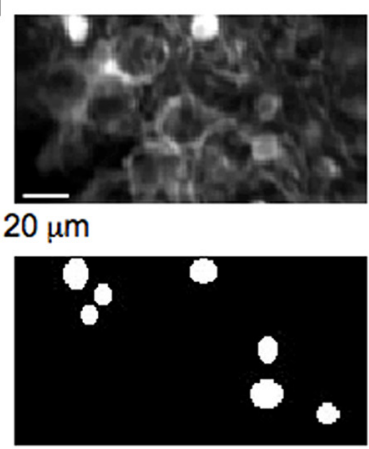

A2

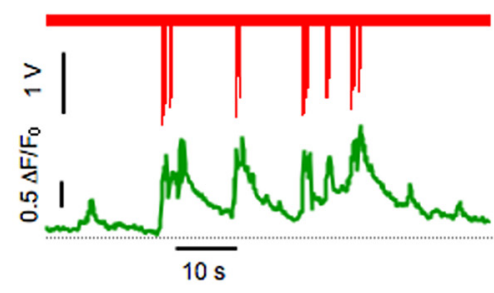

A3

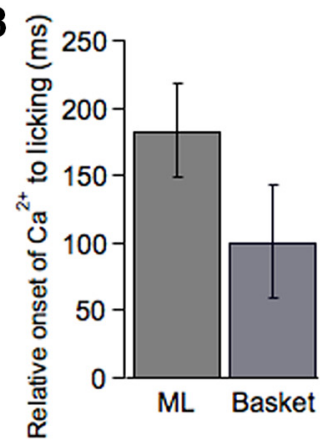

B2

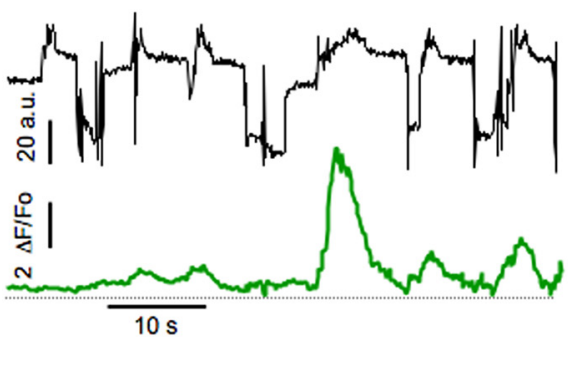

B3

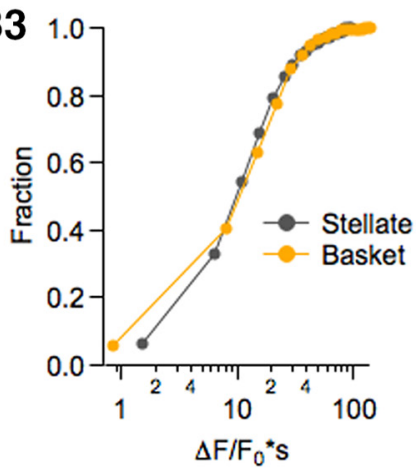

Figure 8. $\quad \mathrm{Ca}^{2+}$ signals in basket cell during licking and bruxing. A1, B1, Two-photon images at the depth of the PC layer showing GCAMP6-expressing basket neurons (top) and R0ls used for analysis (bottom). Note the prominent basket-like structure surrounding the PC soma. $\boldsymbol{A 2}$, Representative example of a licking episode (red trace) and the $\mathrm{Ca}^{2+}$ signal averaged from 16 basket cells (green trace). A3, Mean values for the delay of $\mathrm{Ca}^{2+}$ onset relative to licking do not differ significantly $(t=1.11 ; p>0.2)$ between stellate cells (mean: $183.6 \pm 37.4 \mathrm{ms;} 32$ bursts, 8 imaging runs, $n=5$ mice) and basket cells (mean: $100.9 \pm 42 \mathrm{~ms} ; 10$ bursts from 5 imaging runs, $n=4$ mice). B2, Representative example of jaw motility (black trace) and the corresponding Ca ${ }^{2+}$ signal (green trace) averaged from seven basket cells. $B 3, \mathrm{Ca}^{2+}$ strength during periods of high jaw motility is similar $(t=0.7 ; p=0.5)$ for stellate cells $(788$ cells from 50 imaging runs, $n=3$ mice) and basket cells (480 cells from 43 imaging runs, $n=4$ mice).

(Figs. 4, 5C, 8B), whereas Gaffield and Christie (2017) reported only minimal $\mathrm{Ca}^{2+}$ signals during jaw movements.

\section{Comparison between MLI signals associated with licking and bruxing}

The Crus I and II regions of the cerebellum are involved in processing motor commands sent through the trigeminal nerve to control jaw movements by the anterior temporalis and masseter muscles (for review, see Moore et al., 2014). These regions also receive proprioceptive sensory information likewise provided by the trigeminal nerve. Therefore, the MLI activity observed in the present work is likely to convey a mix of sensory and motor information. However, the two oromotor behaviors showed different spatial and temporal properties, suggesting the engagement of different cerebro-cerebellar circuits in each behavior.

Although it is well known that licking is controlled by a subcortical neural circuit, a central pattern generator (CPG) located in the brainstem, the circuits involved in bruxism are unknown. However, there is increasing evidence to support the hypothesis that this behavior is also initiated in a CPG. A striking example of this is the fact that humans in coma, with no direct cortical motor control, show bruxism episodes (Pratap-Chand and Gourie-Devi, 1985).

Both licking and bruxing are accompanied by jaw movements. The results of Figure 5 show, however, that the amplitudes and kinetics of jaw movements are very different for licking and bruxing. Furthermore, the results of Figures 3 and 4 show that the link between MLI activity and movement is tight for licking, but loose for bruxing. These results indicate that MLI activity does not simply report jaw movement during both licking and bruxing. In addition, the results to be discussed next indicate that, even for licking, the kinetics of MLI activity differ depending on animal motivation. Altogether, MLI activity cannot be considered as a simple reporter of orofacial movement.

\section{Dependence of MLI activity delay on lick number}

The cerebellum has a dual role in regulating fine movement coordination that involves an early processing of feedforward motor commands from the motor cortex or Central Pattern Generators (CPGs) and a late processing of propioceptive sensory feedback. As a result of processing this dual information, the cerebellum produces an error signal that compares feedforward and feedback information. It is likely that the strong MLI activity observed during licking helps to elaborate this error signal. In addition, recent results indicate that granule cells, which drive MLI activity directly, provide reward-linked signals with various latencies during licking (Wagner et al., 2017). Finally, during conditional blink responses, MLI activity develops together with the conditional response, suggesting changes of activity upstream of MLIs during learning (ten Brinke et al., 2015). Overall, MLIs are likely involved in various types of signals displaying distinct time relations with respect to movement.

Strikingly, we find that the delay between MLI activity and licking onset depends on the number of licks contained in a licking burst. For very short bursts (one or two licks), we found no significant lag between the two types of signals (Fig. $3 C$, first bin). Using a slightly different behavioral protocol, Gaffield and Christie (2017) reported a significant delay of $30 \mathrm{~ms}$ for single licks (MLI activity leading onset). Although some of our recordings with one or two licks similarly show a delay in the same direction, 
as exemplified in Figure 3A1, other recordings with one or two licks indicated a delay in the opposite direction, with no net average delay (Fig. 3 C). Given the image acquisition rate in the present study and the limited number of measurements for one or two licks, our data are compatible with the short delay reported in the other study. Overall, the apparent difference between the absence of significant delay for one or two licks in the present work compared with the $30 \mathrm{~ms}$ delay found by Gaffield and Christie (2017) for single licks probably reflects a combination of differences in behavior protocol and recording conditions in the two studies. Importantly, our behavior protocol allowed us to compare also delays for short and long licking bursts in the same sessions. When analyzing these data, we found that, for longer licking bursts (more than four licks/burst; Fig. 3C), licking onset clearly precedes MLI signals, so the sign of the delay is now opposite to that found for one or two licks by Gaffield and Christie (2017). Furthermore, the maximum delay value is $364 \mathrm{~ms}$, more than one order of magnitude larger than that reported by Gaffield and Christie (2017) for one lick. A comparison of licking bursts depending on water availability suggests that very short bursts are exploratory, whereas long bursts aim at immediate water intake (Fig. 3D1-D3). Therefore, very short licking bursts occur in a different context than prolonged bursts and presumably reflect different motivation states of the mouse. These results suggest that the difference of delays is linked to a difference of context between short and long licking bursts. In addition to explaining the difference between short and long licks, the presumed link between MLI signals and motivation may also contribute to explaining the contrast between MLI signals during licking and bruxing.

Our results indicate that, during prolonged licking bursts, the response of MLIs to proprioceptive sensory information occurs once the motor command has been initiated and that it serves to refine the motor output. This view would be consistent with that exposed in a recent discussion about cerebellar involvement on motor control and learning, in which it was proposed that cerebellar projections to the brainstem provide a "temporal coordination" of commands from multiple CPGs during orofacial movements (Lang et al., 2017). Recently, electrophysiological and optogenetic studies of whisking behavior in mice have provided evidence for functional corticocerebellar loops (Proville et al., 2014). If corticocerebellar loops are also involved in shaping orofacial movements, then MLIs could contribute to signal integration.

\section{Coordinated MLI activity during oromotor behavior}

The present finding of simultaneous MLI activity during licking and bruxing indicates that factors promoting binding of MLI activity, including coordinated PF input and synchronization through electrical synapses, prevail on inhibitory MLI-MLI actions through chemical synapses. These results are consistent with our previous findings that, in slices, the driving force for GABAergic synapses is weak (Chavas and Marty, 2003) and that, in vivo, beam activation of PF leads to homogeneous activation of postsynaptic MLIs (Astorga et al., 2015).

The coordinated MLI activity observed in the present study implies that, during bursts of licking, several neighboring MLIs simultaneously send inhibitory signals to downstream PCs. Synaptically isolated PCs respond to current injections of increasing amplitudes with a weakly saturating or nonsaturating frequency/ current relationship up to several hundreds of Hertz (Khaliq and Raman, 2006; Walter and Khodakhah, 2006). If unchecked, strong PF input could therefore elicit excessive PC firing rates.
Based on the present results, it is plausible that coordinated MLI activity serves as a negative feedback effectively limiting the PC firing to physiologically relevant frequency ranges. Therefore, the feedforward inhibition exerted by MLIs presumably serves two distinct purposes: to shorten the duration of PC firing after phasic PF excitation and to restrict the maximum PC firing rate after tonic PF excitation.

\section{References}

Alcami P, Marty A (2013) Estimating functional connectivity in an electrically coupled interneuron network. Proc Natl Acad Sci U S A 110:E4798E4807. CrossRef Medline

Astorga G, Bao J, Marty A, Augustine GJ, Franconville R, Jalil A, Bradley J, Llano I (2015) An excitatory GABA loop operating in vivo. Front Cell Neurosci 9:275. CrossRef Medline

Bao J, Reim K, Sakaba T (2010) Target-dependent feedforward inhibition mediated by short-term synaptic plasticity in the cerebellum. J Neurosci 30:8171-8179. CrossRef Medline

Blot A, de Solages C, Ostojic S, Szapiro G, Hakim V, Léna C (2016) Timeinvariant feed-forward inhibition of Purkinje cells in the cerebellar cortex in vivo. J Physiol 594:2729-2749. CrossRef Medline

Bosman LW, Koekkoek SK, Shapiro J, Rijken BF, Zandstra F, van der Ende B, Owens CB, Potters JW, de Gruijl JR, Ruigrok TJ, De Zeeuw CI (2010) Encoding of whisker input by cerebellar Purkinje cells. J Physiol 588: 3757-3783. CrossRef Medline

Bryant JL, Boughter JD, Gong S, LeDoux MS, Heck DH (2010) Cerebellar cortical output encodes temporal aspects of rhythmic licking movements and is necessary for normal licking frequency. Eur J Neurosci 32:41-52. CrossRef Medline

Byrd KE (1997) Characterization of brux-like movements in the laboratory rat by optoelectronic mandibular tracking and electromyographic techniques. Arch Oral Biol 42:33-43. CrossRef Medline

Cao Y, Maran SK, Dhamala M, Jaeger D, Heck DH (2012) Behavior-related pauses in simple-spike activity of mouse Purkinje cells are linked to spike rate modulation. J Neurosci 32:8678-8685. CrossRef Medline

Carter AG, Regehr WG (2002) Quantal events shape cerebellar interneuron firing. Nat Neurosci 5:1309-1318. CrossRef Medline

Chavas J, Marty A (2003) Coexistence of excitatory and inhibitory GABA synapses in the cerebellar interneuron network. J Neurosci 23:2019-2031. Medline

Chen S, Augustine GJ, Chadderton P (2016) The cerebellum linearly encodes whisker position during voluntary movement. eLife 5:e10509. CrossRef Medline

Chen S, Augustine GJ, Chadderton P (2017) Serial processing of kinematic signals by cerebellar circuitry during voluntary whisking. Nat Commun 8:232. CrossRef Medline

Chen TW, Wardill TJ, Sun Y, Pulver SR, Renninger SL, Baohan A, Schreiter ER, Kerr RA, Orger MB, Jayaraman V, Looger LL, Svoboda K, Kim DS (2013) Ultrasensitive fluorescent proteins for imaging neuronal activity. Nature 499:295-300. CrossRef Medline

Cohen D, Yarom Y (2000) Cerebellar on-beam and lateral inhibition: two functionally distinct circuits. J Neurophysiol 83:1932-1940. Medline

Collin T, Chat M, Lucas MG, Moreno H, Racay P, Schwaller B, Marty A, Llano I (2005) Developmental changes in parvalbumin regulate presynaptic Ca2 + signaling. J Neurosci 25:96-107. CrossRef Medline

Cramer SW, Gao W, Chen G, Ebner TJ (2013) Reevaluation of the beam and radial hypotheses of parallel fiber action in the cerebellar cortex. J Neurosci 33:11412-11424. CrossRef Medline

Dizon MJ, Khodakhah K (2011) The role of interneurons in shaping Purkinje cell responses in the cerebellar cortex. J Neurosci 31:10463-10473. CrossRef Medline

Dzhala V, Valeeva G, Glykys J, Khazipov R, Staley K (2012) Traumatic alterations in GABA signaling disrupt hippocampal network activity in the developing brain. J Neurosci 32:4017-4031. CrossRef Medline

Eccles JC, Llinás R, Sasaki K (1966) The inhibitory interneurones within the cerebellar cortex. Exp Brain Res 1:1-16. Medline

Franconville R, Revet G, Astorga G, Schwaller B, Llano I (2011) Somatic calcium level reports integrated spiking activity of cerebellar interneurons in vitro and in vivo. J Neurophysiol 106:1793-1805. CrossRef Medline

Gaffield MA, Christie JM (2017) Movement rate Is encoded and influenced by widespread, coherent activity of cerebellar molecular layer interneurons. J Neurosci 37:4751-4765. CrossRef Medline 
Gaffield MA, Amat SB, Bito H, Christie JM (2016) Chronic imaging of movement-related Purkinje cell calcium activity in awake behaving mice. J Neurophysiol 115:413-422. CrossRef Medline

Häusser M, Clark BA（1997） Tonic synaptic inhibition modulates neuronal output pattern and spatiotemporal synaptic integration. Neuron 19:665678. CrossRef Medline

Hayar A, Bryant JL, Boughter JD, Heck DH (2006) A low-cost solution to measure mouse licking in an electrophysiological setup with a standard analog-to-digital converter. J Neurosci Methods 153:203-207. CrossRef Medline

Heiney SA, Kim J, Augustine GJ, Medina JF (2014) Precise control of movement kinematics by optogenetic inhibition of Purkinje cell activity. J Neurosci 34:2321-2330. CrossRef Medline

Jelitai M, Puggioni P, Ishikawa T, Rinaldi A, Duguid I (2016) Dendritic excitation-inhibition balance shapes cerebellar output during motor behaviour. Nat Commun 7:13722. CrossRef Medline

Jörntell H, Ekerot CF (2003) Receptive field plasticity profoundly alters the cutaneous parallel fiber synaptic input to cerebellar interneurons in vivo. J Neurosci 23:9620-9631. Medline

Jörntell H, Bengtsson F, Schonewille M, De Zeeuw CI (2010) Cerebellar molecular layer interneurons: computational properties and roles in learning. Trends Neurosci 33:524-532. CrossRef Medline

Khaliq ZM, Raman IM (2006) Relative contributions of axonal and somatic $\mathrm{Na}$ channels to action potential initiation in cerebellar Purkinje neurons. J Neurosci 26:1935-1944. CrossRef Medline

Kim J, Lee S, Tsuda S, Zhang X, Asrican B, Gloss B, Feng G, Augustine GJ (2014) Optogenetic mapping of cerebellar inhibitory circuitry reveals spatially biased coordination of interneurons via electrical synapses. Cell Rep 7:1601-1613. CrossRef Medline

Lang EJ, Apps R, Bengtsson F, Cerminara NL, De Zeeuw CI, Ebner TJ, Heck DH, Jaeger D, Jörntell H, Kawato M, Otis TS, Ozyildirim O, Popa LS, Reeves AM, Schweighofer N, Sugihara I, Xiao J (2017) The roles of the olivocerebellar pathway in motor learning and motor control: a consensus paper. Cerebellum 16:230-252. CrossRef Medline

Lee KH, Mathews PJ, Reeves AM, Choe KY, Jami SA, Serrano RE, Otis TS (2015) Circuit mechanisms underlying motor memory formation in the cerebellum. Neuron 86:529-540. CrossRef Medline

Mann-Metzer P, Yarom Y (1999) Electrotonic coupling interacts with intrinsic properties to generate synchronized activity in cerebellar networks of inhibitory interneurons. J Neurosci 19:3298-3306. Medline

Middleton SJ, Racca C, Cunningham MO, Traub RD, Monyer H, Knöpfel T, Schofield IS, Jenkins A, Whittington MA (2008) High-frequency network oscillations in cerebellar cortex. Neuron 58:763-774. CrossRef Medline

Mittmann W, Koch U, Häusser M (2005) Feed-forward inhibition shapes the spike output of cerebellar Purkinje cells. J Physiol 563:369-378. CrossRef Medline

Moore JD, Kleinfeld D, Wang F (2014) How the brainstem controls orofacial behaviors comprised of rhythmic actions. Trends Neurosci 37:370380. CrossRef Medline

Orduz D, Llano I (2007) Recurrent axon collaterals underlie facilitating synapses between cerebellar Purkinje cells. Proc Natl Acad Sci U S A 104: 17831-17836. CrossRef Medline
Ozden I, Dombeck DA, Hoogland TM, Tank DW, Wang SS (2012) Widespread state-dependent shifts in cerebellar activity in locomoting mice. PLoS One 7:e42650. CrossRef Medline

Palay S L, Chan-Palay V (1974) Cerebellar cortex: cytology and organization. Berlin: Springer.

Pratap-Chand R, Gourie-Devi M (1985) Bruxism: its significance in coma. Clin Neurol Neurosurg 87:113-117. CrossRef Medline

Proville RD, Spolidoro M, Guyon N, Dugué GP, Selimi F, Isope P, Popa D, Léna C (2014) Cerebellum involvement in cortical sensorimotor circuits for the control of voluntary movements. Nat Neurosci 17:12331239. CrossRef Medline

Rheims S, Holmgren CD, Chazal G, Mulder J, Harkany T, Zilberter T, Zilberter Y (2009) GABA action in immature neocortical neurons directly depends on the availability of ketone bodies. J Neurochem 110:13301338. CrossRef Medline

Santamaria F, Tripp PG, Bower JM (2007) Feedforward inhibition controls the spread of granule cell-induced Purkinje cell activity in the cerebellar cortex. J Neurophysiol 97:248-263. CrossRef Medline

Schneider CA, Rasband WS, Eliceiri KW (2012) NIH Image to ImageJ: 25 years of image analysis. Nat Methods 9:671-675. CrossRef Medline

Szapiro G, Barbour B (2007) Multiple climbing fibers signal to molecular layer interneurons exclusively via glutamate spillover. Nat Neurosci 10: 735-742. CrossRef Medline

ten Brinke MM, Boele HJ, Spanke JK, Potters JW, Kornysheva K, Wulff P, IJpelaar AC, Koekkoek SK, De Zeeuw CI (2015) Evolving models of Pavlovian conditioning: Cerebellar cortical dynamics in awake behaving mice. Cell Rep 13:1977-1988. CrossRef Medline

Thompson SM, Gähwiler BH (1989) Activity-dependent disinhibition. I. Repetitive stimulation reduces IPSP driving force and conductance in the hippocampus in vitro. J Neurophysiol 61:501-511. Medline

Vincent P, Marty A (1996) Fluctuations of inhibitory postsynaptic currents in Purkinje cells from rat cerebellar slices. J Physiol 494:183-199. CrossRef Medline

Wagner MJ, Kim TH, Savall J, Schnitzer MJ, Luo L (2017) Cerebellar granule cells encode the expectation of reward. Nature 544:96-100. CrossRef Medline

Walter JT, Khodakhah K (2006) The linear computational algorithm of cerebellar Purkinje cells. J Neurosci 26:12861-12872. CrossRef Medline

Welsh JP, Lang EJ, Suglhara I, Llinás R (1995) Dynamic organization of motor control within the olivocerebellar system. Nature 374:453-457. CrossRef Medline

Witter L, Rudolph S, Pressler RT, Lahlaf SI, Regehr WG (2016) Purkinje cell collaterals enable output signals from the cerebellar cortex to feed back to Purkinje cells and interneurons. Neuron 91:312-319. CrossRef Medline

Wulff P, Schonewille M, Renzi M, Viltono L, Sassoè-Pognetto M, Badura A, Gao Z, Hoebeek FE, van Dorp S, Wisden W, Farrant M, De Zeeuw CI (2009) Synaptic inhibition of Purkinje cells mediates consolidation of vestibulo-cerebellar motor learning. Nat Neurosci 12:1042-1049. CrossRef Medline

Zilberter Y, Zilberter T, Bregestovski P (2010) Neuronal activity in vitro and the in vivo reality: the role of energy homeostasis. Trends Pharmacol Sci 31:394-401. CrossRef Medline 